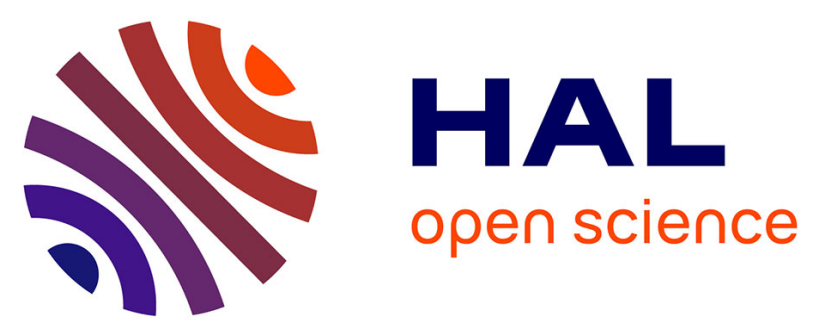

\title{
The path for innovative severe accident neutronics studies in ZPRs. Part I.2: Interpretation of SNEAK-12A experiment for core disruption in LMFBRs impact of nuclear data uncertainties on reactivity coefficients
}

\author{
M. Margulis, Patrick Blaise, Frederic Mellier, Erez Gilad
}

\section{To cite this version:}

M. Margulis, Patrick Blaise, Frederic Mellier, Erez Gilad. The path for innovative severe accident neutronics studies in ZPRs. Part I.2: Interpretation of SNEAK-12A experiment for core disruption in LMFBRs impact of nuclear data uncertainties on reactivity coefficients. Progress in Nuclear Energy, 2017, 96, pp.97-117. 10.1016/j.pnucene.2016.12.006 . cea-02389231

\section{HAL Id: cea-02389231 \\ https://hal-cea.archives-ouvertes.fr/cea-02389231}

Submitted on 2 Dec 2019

HAL is a multi-disciplinary open access archive for the deposit and dissemination of scientific research documents, whether they are published or not. The documents may come from teaching and research institutions in France or abroad, or from public or private research centers.
L'archive ouverte pluridisciplinaire HAL, est destinée au dépôt et à la diffusion de documents scientifiques de niveau recherche, publiés ou non, émanant des établissements d'enseignement et de recherche français ou étrangers, des laboratoires publics ou privés. 


\title{
The path for innovative severe accident neutronics studies in ZPRs. Part I.2: Interpretation of SNEAK-12A experiment for core disruption in LMFBRs impact of nuclear data uncertainties on reactivity coefficients
}

\author{
M. Margulis ${ }^{\mathrm{a}, \mathrm{b}, *}$, P. Blaise ${ }^{\mathrm{a}}$, F. Mellier ${ }^{\mathrm{a}}$, E. Gilad ${ }^{\mathrm{b}}$ \\ ${ }^{a} \mathrm{DEN} / \mathrm{CAD} / \mathrm{DER} / \mathrm{SPEx} / \mathrm{LPE}$, CEA Cadarache, Saint-Paul-lez-Durance 13108, France \\ ${ }^{b}$ The Unit of Nuclear Engineering, Ben-Gurion University of the Negev, Beer-Sheva 84105, Israel
}

\begin{abstract}
The present work details a further investigation of the SNEAK-12A experimental program, which aimed to study material relocation in Sodium Fast Reactors (SFRs) leading to core degradation. The further investigation include sensitivity and uncertainty propagation analysis. In this paper, a comparison is made using two codes, a Monte Carlo based code Serpent 2 and the deterministic system code ERANOS. A sensitivity analysis was made utilizing the two codes, with comparison of two nuclear data libraries (ENDF/B-VII.1 and JEFF-3.1.1). The code-to-code comparison resulted in a very good agreement, while the comparison of libraries showed large discrepancies, manly due to the differences in the sodium cross-section data. The sensitivity analysis, was followed by a complete propagated uncertainty analysis based on the covariance evaluated data available in the COMAC data evaluation. The results of the uncertainties show that there are still large discrepancies linked to the nuclear data. This work is done within the frame work of new core design capacities and new ways of conducting in Zero Power Reactors, such as the ZEPHYR project led independently by CEA.
\end{abstract}

Keywords: SNEAK-12A, Core disruption, Severe accidents, Reactivity coefficient, Nuclear data, Sensitivity, Uncertainty

\section{Introduction}

Target accuracy is one of the most active field of research in nuclear reactor studies. The emergence of High Performance Computing (HPC), and the groing use of Monte Carlo methods even in pre-industrial calculations reduce the impact of calculation scheme uncertainties and concentrate the effort on the reduction of nuclear data uncertainties, as they are now commonly regarded as being the most important source of propagated uncertainties on integral data. The most significant recent initiative aiming to systematic nuclear data uncertainty impact assessment, was taken by the Working Party on Evaluation Cooperation (WPEC) of the OECD/NEA when it established a subgroup number 26

\footnotetext{
*M. Margulis

Email address: marat.margulis@cea.fr, maratm@post.bgu.ac.il (M. Margulis)
} 
to develop a systematic approach to define the data required for advanced reactor systems and to make an evaluations of such needs for the future Generation-IV (Gen-IV) reactors ( Salvatores et al. (2008)). A comprehensive sensitivity and uncertainty study was performed to evaluate the impact of propagated uncertainty from nuclear cross-section data on different parameters related to the core and fuel cycle of a wide range of systems, even beyond Gen-IV systems.

Core parameter uncertainties are assessed with propagation both of the design and nuclear data uncertainties. Design uncertainties are associated with the design margins and their dependency on core geometries, materials and assessing working parameters. Nuclear data uncertainties gather the uncertainties impeded in microscopic measurements (transmission by time-of-flight, detector efficiency, etc.) and the nuclear physics model uncertainties used to fit the previous measurements. Ideally the uncertainties should be provided in a form of covariance matrices from the production process of nuclear data libraries. To obtain reliable covariances associated with the JEFF-3.1.1 evaluations ( Santamarina et al. (2009)), a nuclear data re-assessment of major isotopes was performed thanks to selected targeted integral experiments ( Santamarina et al. (2012)). This dedicated work led to the generation of a new set of covariance matrices linked to the JEFF-3.1.1 libraries - the COvariance MAtrices Cadarache (COMAC) ( De Saint Jean et al. (2012)).

One of the major parameter to manage in future Gen-IV reactors is the sodium void reactivity coefficient, and its impact on the safety behavior of such system. In particular, the future French ASTRID industrial demonstrator is characterized by a negative void coefficient, increasing the margin of safe unprotected transient recovery. However, this point must be fully validated, in particular during unconventional situations, such as off-normal transients. A large number of integral experiments in critical facilities were performed worldwide to assess Na void measurements, and also covered $\mathrm{Na}$ void related to SCA situations. Among them, the most comprehensive and complete set of experiments were conducted in the SNEAK fast critical facility.

The SNEAK-12A experimental program ( Helm \& Henneges (1985); Helm et al. (1984); Margulis et al. (2016a,b)) operated during the 80 s in the Karlsruhe center (KfK). The aim of the program was to study neutronic behavior during large material relocation inside a hypothetical liquid-metal fast breeder reactor (LMFBR) configuration. The experimental programs included experiments such as - structure material relocation, fuel slump-in and slump-out, fuel compaction of different magnitudes and radial molten pool expansion. Those experiments were utilized for code validation like SIMMER ( Helm et al. (1984)) and Monte Carlo based codes - Serpent, Tripoli and MCNP ( Margulis 35 et al. (2016a,b)).

The SNEAK-12A program supplied some in sites for core behavior under severe core accident (SCA) conditions. Although SNEAK-12A core was loaded mainly with metallic uranium fuel, which is not considered in the next generation fast reactors. More realistic MOX fuel was used in the SNEAK-12B program, which is currently being analyzed in CEA Cadarache, and will be published later. Unfortinatly, the SNEAK-12A program did not provide essential key parameters such as axial traverses and different core parameters due to technological deficient. However, these parameters are of high importance. Therefore, an innovative program was initiated in CEA Cadarache (France) with a collaboration of Ben Gurion University of the Negev (Israel) for future experimental program design that 
would be implemented in the Zero power Experimental PHYsics Reactor (ZEPHYR) ( Blaise et al. (2016)),currently being designed at CEA. The program aims to study neutronic behavior of fast reactors during large scale SCA in fast reactors, utilizing a fast/thermal approach core concept for fissile material economy.

This paper presents a further investigation of the SNEAK-12A core, concentrating mainly on the sensitivity and the uncertainty studies to evaluate the impact of neutron cross section uncertainty on the core reactivity. The entire program, in the frame work of which those experiments are evaluated, studies the possibility of recriticality of a fast reactor due to material relocation, the parameter of interest is the reactivity changes between different states of SCA progression. The performed study can provide an indication on which nuclear data of the examined isotopes is in need for adjustment in light of the presented experiments in order to assure a more accurate calculation and reduce the safety margins required to take in to account due to nuclear data uncertainties in future experimental design.

\section{Methodology}

As mentioned previously, a further analysis of the SNEAK-12A was made in order to study the effect of the cross-section data on the future experiments design. The calculation where carried out mainly with the JEFF-3.1.1 cross-section libraries. However, impact of a different cross-section libraries on the sensitivity profiles was made, with utilization of the ENDF-B/VII.1. For all the experimental configurations, the impact of nuclear data uncertainty for several isotopes is studied $\left({ }^{12} \mathrm{C},{ }^{16} \mathrm{O},{ }^{23} \mathrm{Na},{ }^{27} \mathrm{Al},{ }^{56} \mathrm{Fe},{ }^{58} \mathrm{Ni},{ }^{235} \mathrm{U}\right.$ and $\left.{ }^{238} \mathrm{U}\right)$, those isotopes having the largest impact on the system. Each isotope information (cross-section, differential data, covariances) are processed in 33 energy groups for the perturbation calculations.

\subsection{Sensitivity coefficients and uncertanties calculation}

Generally, the sensitivity coefficient $S$ of a response parameter $R$ against the perturbed parameter $\alpha$ is defined as -

$$
S=\frac{\Delta R}{R} \mid \frac{\Delta \alpha}{\alpha}
$$

In this work case the response parameter is the core effective multiplication factor $\left(\mathrm{k}_{\mathrm{eff}}\right)$ and the perturbed parameter is the macroscopic cross-section $(\Sigma)$. The estimation sensitivity coefficients of $\mathrm{k}_{\text {eff }}$ is performed according to a formula which is derived from the classical standard perturbation theory -

$$
S_{k, \Sigma_{r, n}}=-\frac{\Sigma_{r, n}}{k_{\mathrm{eff}}} \frac{\left\langle\phi^{+}\left(\frac{\partial A}{\partial \Sigma_{r, n}}-\frac{1}{k_{\mathrm{eff}}} \frac{\partial B}{\partial \Sigma_{r, n}}\right) \phi\right\rangle}{\left\langle\phi^{+} \frac{B}{k_{\mathrm{eff}}^{2}} \phi\right\rangle}
$$

Where $A$ and $B$ are the loss and production operators respectively, $\phi$ is the angular neutron flux with $\phi^{+}$is the adjoint operator, $\Sigma_{r, n}$ is the incidental macroscopic cross-section of isotope $n$ and response $r$ and $S_{k, \Sigma_{r, n}}$ is the energy dependent sensitivity vector.In essence, the $\partial A / \partial \Sigma_{n, r}$ and $\partial B / \partial \Sigma_{n, r}$ expressions in Eq. 2 are representing functions of 
scattering, capture and fission cross-section data respectively. The evaluation of Eq. 2 is essentially integration of the forward and adjoint fluxes and the cross-sections over the entire phase space.

Several codes available today enable to perform calculation of the sensitivity profiles for different isotopes and cross-section data. One of the most widely used codes is the European Reactor ANalysis Optimized calculation System (ERANOS) code system ( Rimpault et al. (2002)). The ERANOS code system has been developed and extensively validated with the aim of providing a suitable basis for reliable neutronic calculations of current as well as advanced fast reactor cores. In order to perform sensitivity analysis, ERANOS utilizes discrete ordinates transport theory (SN-calculation) in R-Z geometry. However, more general 2D and 3D geometries are available.

The second and one of the most recent codes to be implemented with sensitivity/perturbation calculation capabilities is the continuous energy Monte Carlo based code Serpent ( Leppanen et al. (2015)). The new implemented collision-based approach ( Aufiero et al. (2015)) allows the calculation of the effects on nuclear data on several response reactions $\left(\mathrm{k}_{\mathrm{eff}}, \beta_{\mathrm{eff}}\right.$ etc.) Serpent results were compared to ERANOS,considered as the reference tool for Sensitivity and Uncertainty Analysis (SUA), for two fast metallic systems (Flattop and Jezebel), which showed excellent agreement between the codes ( Aufiero et al. (2015)). The most important feature of Serpent with respect to ERANOS, is the utilization of an exact 3-dimensional (3D) model for core calculation. Moreover, all calculation were made in 33-energy group structure used in the ECCO lattice module of ERANOS.

After obtaining the sensitivity vectors (as function of energy) from ERANOS and Serpent, the next step would be to calculate the propagated uncertainties from the cross-section data using the COMAC matrices ( De Saint Jean et al. (2012)). The variance for the $\mathrm{k}_{\mathrm{eff}}$ is determined as -

$$
\sigma_{k_{n, r}}^{2}=S_{k, \Sigma_{n, r}} C_{\Sigma_{n, r}, \Sigma_{n, r}} S_{k, \Sigma_{n, r}}^{t}
$$

where $C_{\Sigma_{n, r}, \Sigma_{n, r}}$ is the covariance matrix of size $S \times S$ corresponding to isotope $n$ and reaction $r$. The typical treatment of uncertainties contains mainly energy-correlated responses for different isotopes (e.g for ${ }^{238} \mathrm{U}$ capture-capture cross-sections). However, in the COMAC matrix "un-correlated" (or "non block-diagonal") responses linked to the data assimilation process used in COMAC are included for several important isotopes (e.g for ${ }^{238} \mathrm{U}$ capture-fission cross-sections), thus allowing the final result be more realistic (i.e the off-diagonal correlations represent a physical constraint in the process of differential measurement analysis, such as: a total cross section is the sum of its partials, hence correlating the capture to the fission).

\subsection{The physics of sodium void and material relocation}

The subject of sodium voiding was reviewed many times by different experimental programs during the history (e.g ZEBRA-8G and ZEBRA-12 ( Collins \& Ingram (1973)), ZPPR-5 Kaiser et al. (1976), ZPPR-9 ( Curtis et al. (1979)), FCA VIII-2 ( Nakano et al. (1984)) and more) makes the physics of reactivity changes due to sodium voiding well established. Let's consider the multi-group diffusion theory: the reactivity change from the reference to the 
perturbed configuration may be written as -

$$
\Delta \rho=\rho^{\prime}-\rho=\frac{\partial k}{k k^{\prime}}=\frac{\frac{P}{k}+S-A-L}{N}
$$

Each parameter in Eq. 4 is an integrated function with depends on the adjoint flux (importance) of the reference configuration and the forward flux of the perturbed system ( Tommasi et al. (2010)). For sodium voiding, we are experiencing the following trends -

- production contribution $P$ - the cross-section variation is only due to the change (increase) in self-shielding due to the sodium removal. Therefore, $P$ is usually of small magnitude;

- scattering contribution $S$ - the scattering cross-section change due to sodium removal is negative. However, there is a strong effect of type of the fuel that is loaded in to the core, as it would affect the down scattering importance change. Generally in case of sodium voiding in fast reactors, the value of $S$ is positive;

- absorption contribution $A$ - there is a direct influence on the term due to sodium removal in the general absorption term. However, this is considered to have a small impact;

- leakage contribution $L$ - the diffusion coefficient change in case of sodium voiding is positive as sodium is being removed. Therefore, is considered to be positive;

- normalization factor $N$ - is used for scaling the results to reactivity changes $(\mathrm{N}>0)$.

On the other hand, fissile material relocation mainly affects the leakage factor $(L)$, by reducing its value. The change can be quite significant and can lead to high positive reactivity insertion.

On the grounds of the presented SCA sequences, we can re-introduce Eq. 4 in a more convenient form of production $(P C)$ and a leakage $(L C)$ components, as shown in Eq. 5. Thus, it is possible to say that for sodium voiding the reactivity change might be negative when the $L C$ becomes greater than the $P C$. On the other hand, when fissile material compaction examined the reactivity change is strongly dependent on the amount of the compacted material.

$$
\partial \rho=P C+L C=\frac{\frac{P}{k}-S-A}{N}-\frac{L}{N}
$$

As mentioned previously in this section, the sensitivity is strongly linked to the macroscopic cross-section (Eq. 1) of particular isotopes. It is here interesting to quantify the impact cross section uncertainties on the reactivity changes due to both $\mathrm{Na}$ voiding and fuel/material relocation. In the SNEAK-12A experimental program, the fuel relocation was made with the entire initial fuel loading remaining in the core, when the only material being removed was the sodium. The different reviewed experiments of the SNEAK-12A program will be described later in the text. However, it should be pointed out now that each of the SCA scenarios is initiated by sodium void. Therefore, it would be possible to derive the effect of sodium removal and the material relocation on the nuclear data propagated uncertainties. 
The sodium evaluated data in the ENDF/B-VII.1 and JEFF-3.1.1 files exhibits significant differences, older nuclear data comparison were made between ENDF/B-VII.0 and JEFF-3.1 cross-section libraries ( Rimpault et al. (2007); Tommasi et al. (2010)). The later libraries in this work experience similar discrepancies between the examined crosssection data. Large discrepancies appear in the high energy range, an example for such discrepancy is shown in Figs. 1 to 4 . In this work the impact of the angular distribution on the uncertainties was not studied, due to the lack of covariance data for the ENDF nuclear data libraries.

- the ENDF/B-VII.1 total ${ }^{23} \mathrm{Na}$ cross-section is lower between $0.6-3 \mathrm{MeV}$ and higher between 3 - $10 \mathrm{MeV}$;

- the ENDF/B-VII.1 inelastic scattering cross-section is higher by more then $50 \%$ in energies above $2 \mathrm{MeV}$ (Fig. 2);

- the ENDF/B-VII.1 elastic scattering cross-section is lower by about $20 \%$ in range of $1-10 \mathrm{MeV}$ (Fig. 3);

- there is a large difference in the elastic scattering angular distribution between the different libraries (Fig. 4).

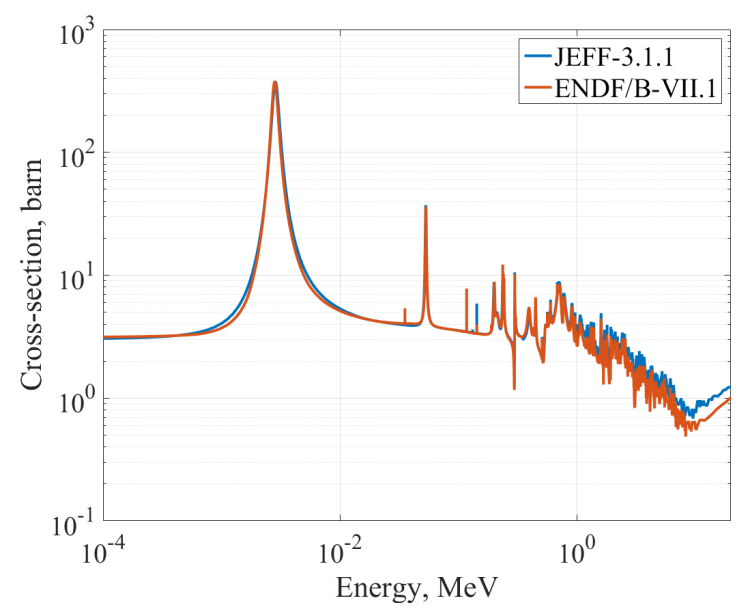

(a) Elastic cross-section

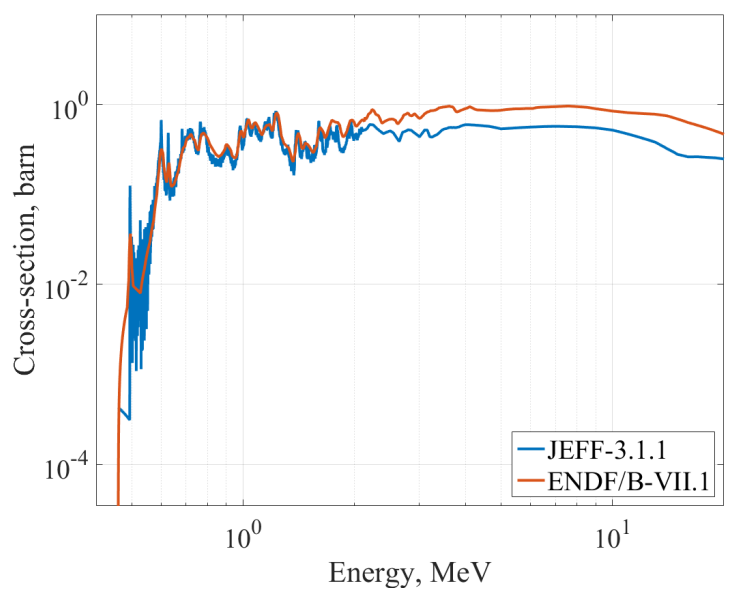

(b) Inelastic cross-section

Figure 1: ${ }^{23} \mathrm{Na}$ cross-section for ENDF/B-VII.1 and JEFF-3.1.1 evaluations

The effect of the different libraries on the sensitivity profiles was studied in this work. However, due to unavailability of covariance data associated with ENDF/B-VII nuclear data, the propagation of the nuclear data uncertainties would be performed using COMAC covariance data, which is linked to the JEFF nuclear data. In order to compute the sensitivity of the different configuration changes on the nuclear data, one required to compute the sensitivity profiles for each configuration, according to Eq. 2. Then, by utilizing the "equivalent generalized perturbation theory" (EGPT) formalism (Gandini et al. (1986)) for reactivity changes allows to express the sensitivity of a reactivity variation to 


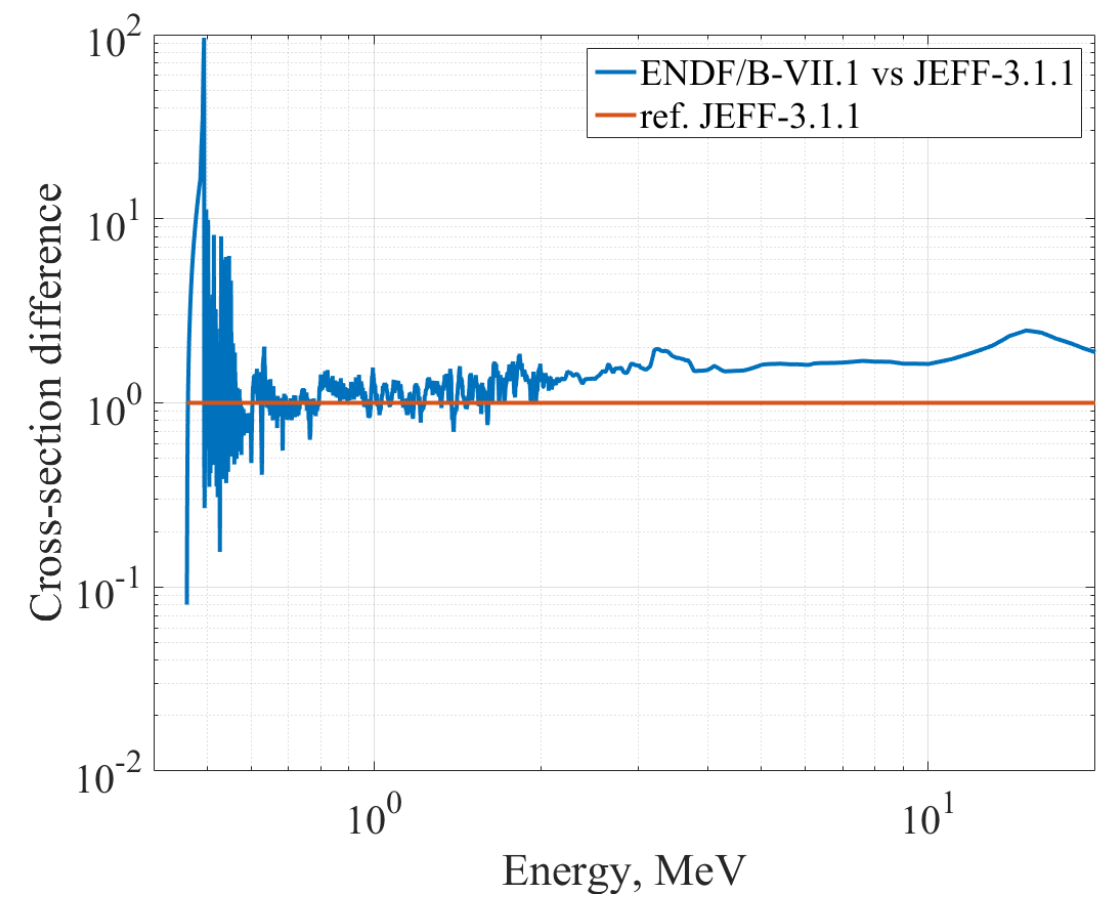

Figure 2: ${ }^{23} \mathrm{Na}$ total inelastic scattering cross-section - ENDF/B-VII.1 compared to JEFF-3.1.1.

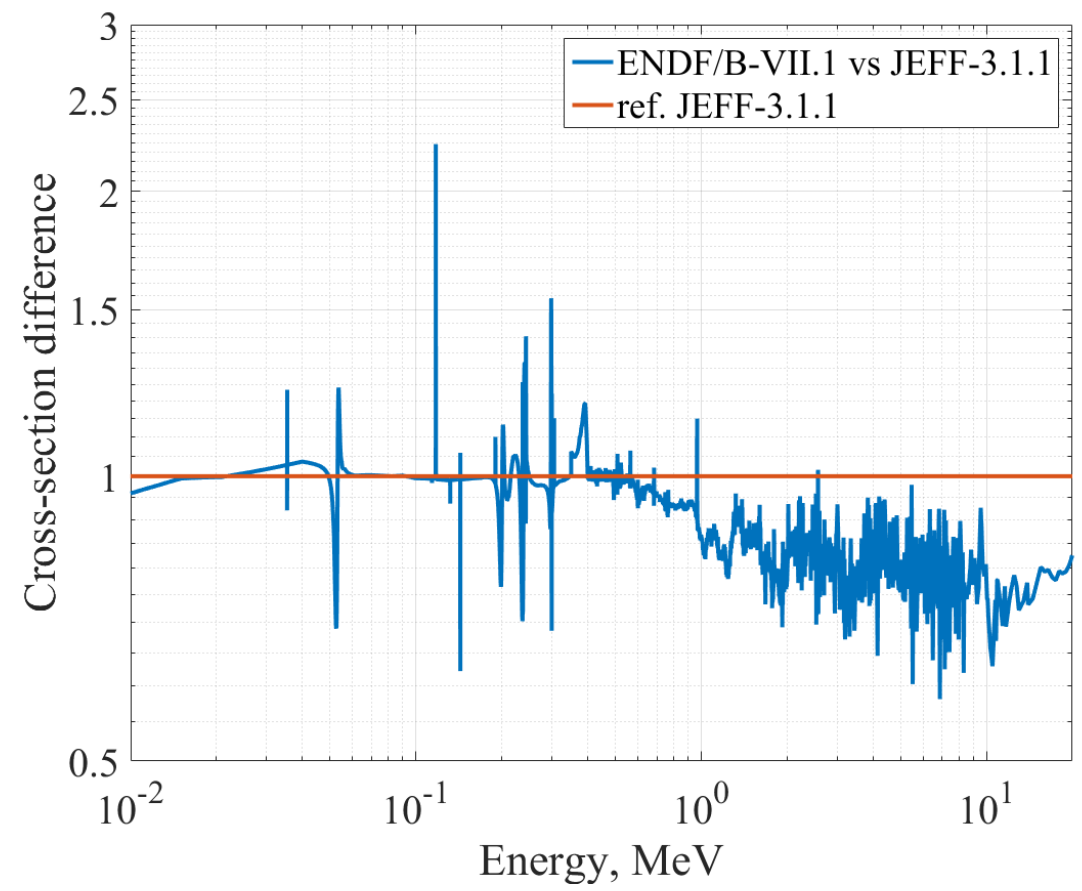

Figure 3: ${ }^{23} \mathrm{Na}$ total elastic scattering cross-section - ENDF/B-VII.1 compared to JEFF-3.1.1. 


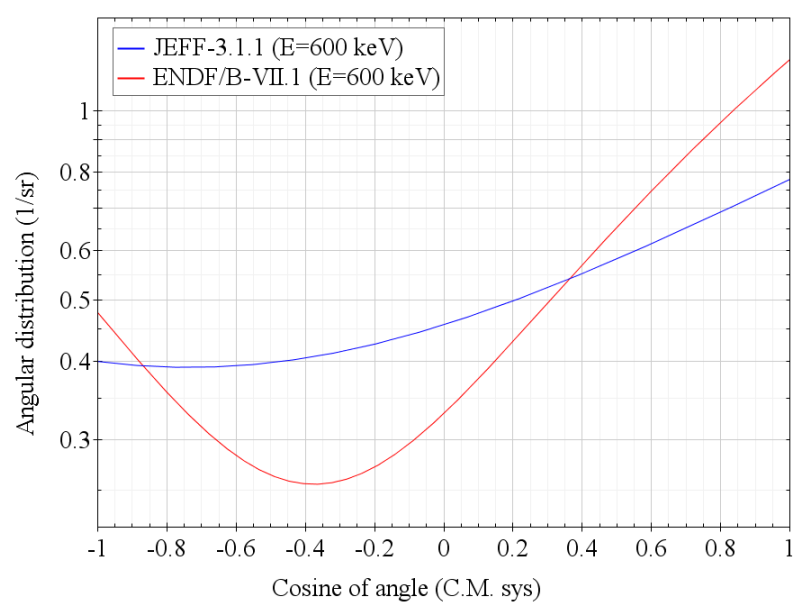

(a) Incident neutron energy $=600 \mathrm{keV}$.

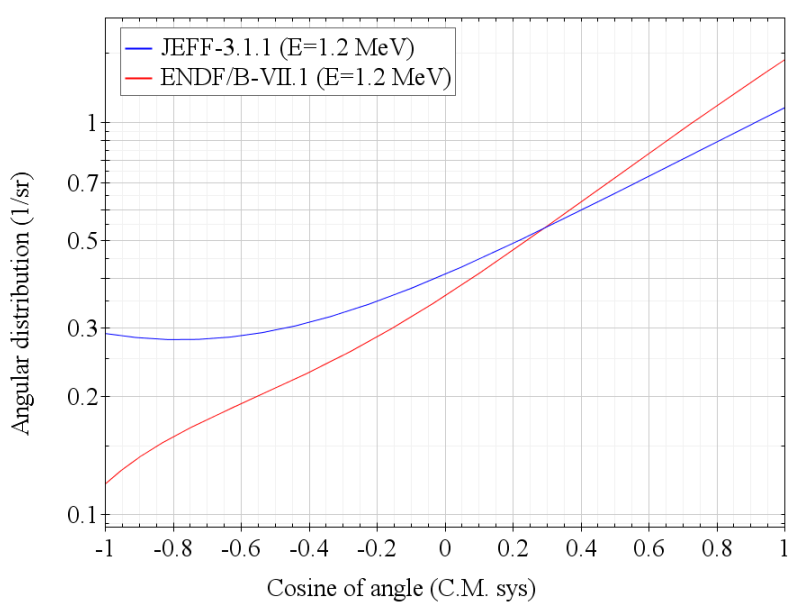

(b) Incident neutron energy $=1.2 \mathrm{MeV}$.

Figure 4: JEFF-3.1.1 vs. ENDF/B-VII.1 angular distribution for the elastic cross-section for ${ }^{23} \mathrm{Na}$.

nuclear data as -

$$
S\left(\Delta \rho, \Sigma_{n, r}\right)=\frac{1}{\Delta \rho}\left(\frac{S\left(k_{2}, \Sigma_{n, r}\right)}{k_{2}}-\frac{S\left(k_{1}, \Sigma_{n, r}\right)}{k_{1}}\right)
$$

where $\rho$ stands for reactivity, $k$ is the effective multiplication factor of the two different core configurations: 1 (the reference one) and 2 (the perturbed one).

\section{SNEAK-12A Benchmark problem}

As it was mentioned, the benchmark configuration that is under review in this work based on the SNEAK-12A experimental program. The SNEAK-12A is a enriched metallic uranium fuel plate type core aimed to simulate insertions of up to $1.5 \$$. The static analysis of the experiments showed excellent agreement between MC codes (Serpent, TRIPOLI4, MCNP5)( Margulis et al. (2016a,b)) and a fairly good agreement with ERANOS v2.4, mainly due to the simplified R-Z treatment of the geometry. This paper would concentrate on two SA based scenarios taken from the SNEAK-12A program. sodium was removed from several central zone fuel assemblies and fuel was compacted near one axial end of the core, as shown in Fig 7. For each experiment a different core loading was made, starting with 4 up to 36 affected fuel elements.

The second scenario was carried out on two magnitudes, small (4 affected assemblies) and large (16 affected 
slump-in surrounded by voided regions. The third step included a large material accumulation around the core midplate. The last step corresponds to the molten pool configuration from the previous scenario, as demonstrated in Fig. 8 for a small scale SCA.

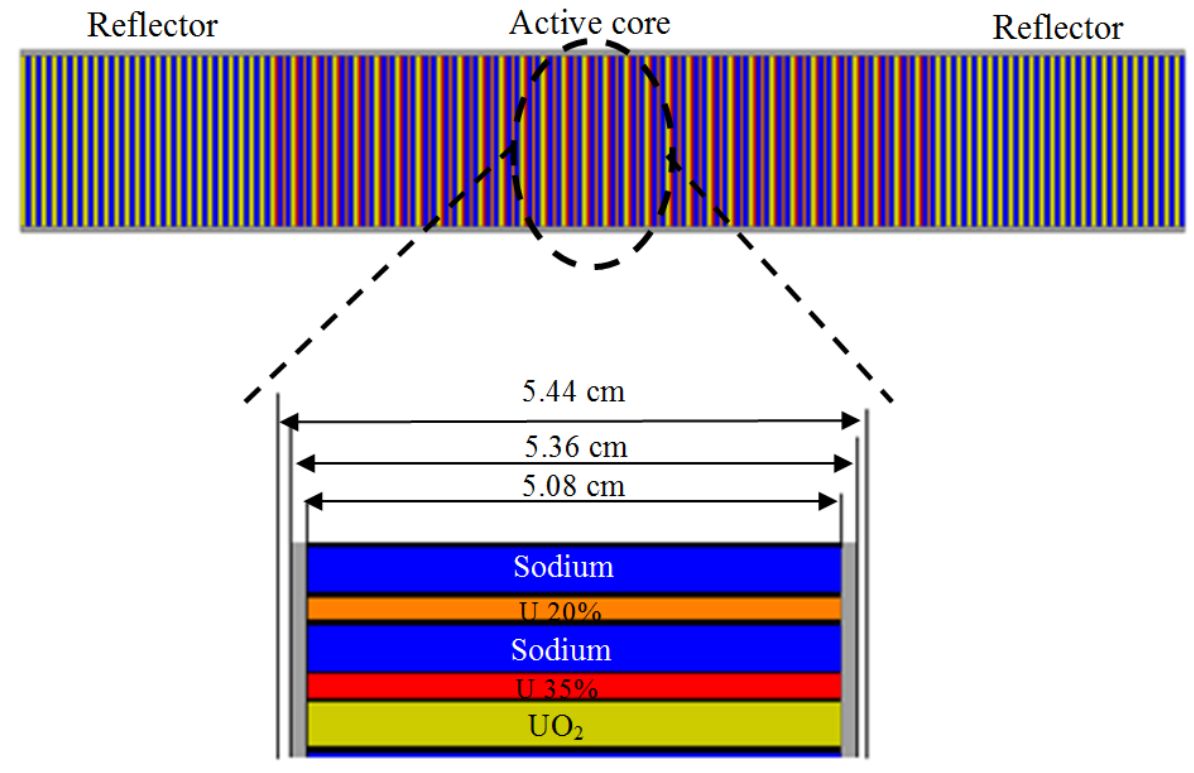

Figure 5: SNEAK-12A normal fuel assembly element.
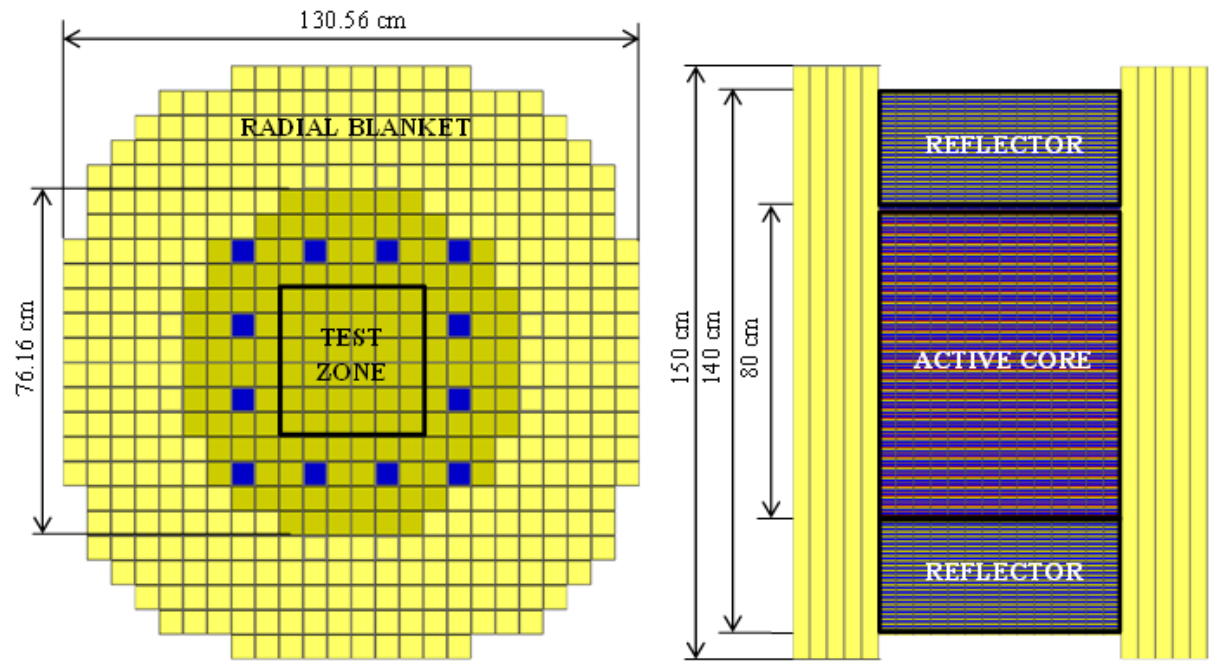

Figure 6: SNEAK-12A normal core loading. Red color - indicate control rods 

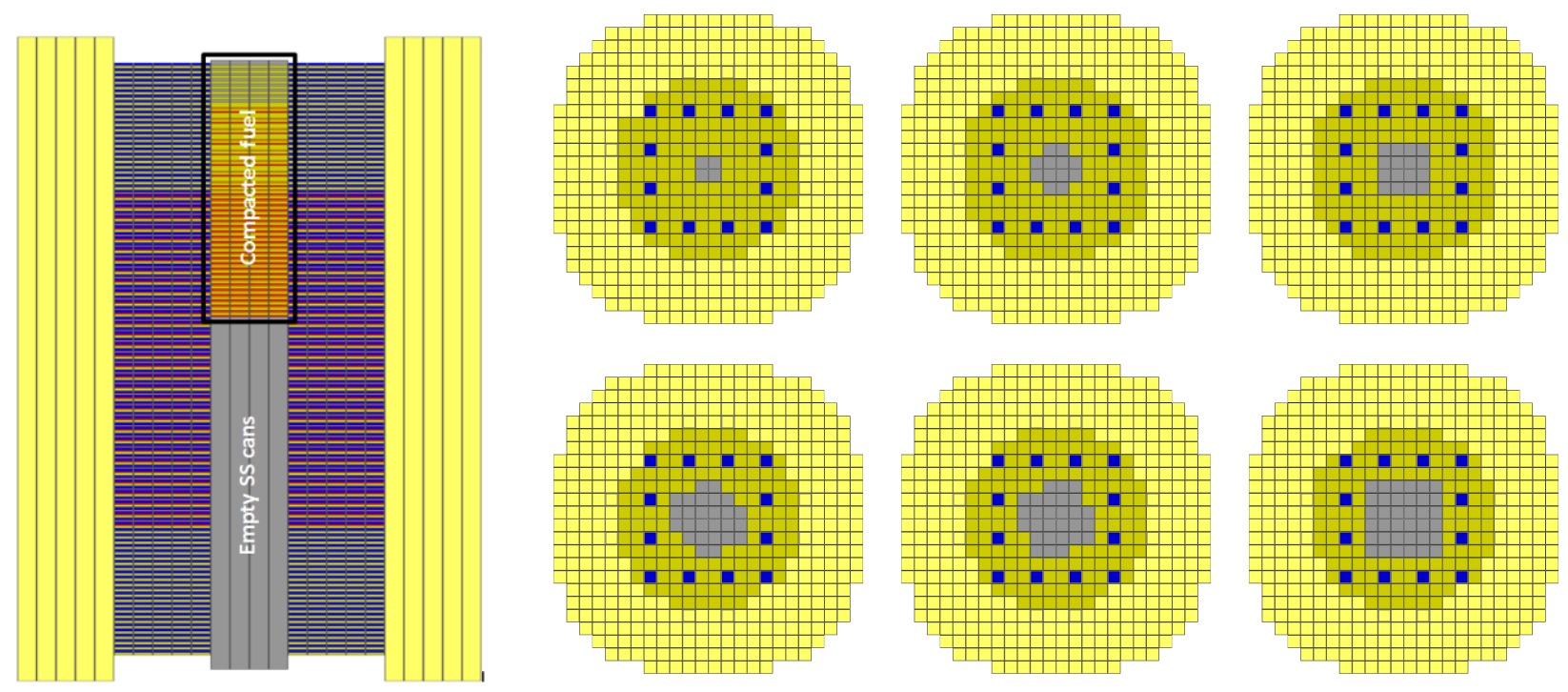

Figure 7: SNEAK-12A molten pool configuration (indicate affected area (gray))

\section{Results}

\subsection{Clear criticality core configuration sensitivity and uncertainty analysis results}

The sensitivity profiles provided some details on the governing physical mechanisms, like the dominant reaction types and energy ranges, that influence particle transport in a particular experiment. Moreover, comparing both the experimental and calculated parameters as well as the sensitivities between different experiments, substantially increases the amount of information which can be deduced from the experiments, rather than just comparing the values.

The cross-section sensitivity analysis of the SNEAK-12A core is initially made on the clear core configuration in order to determine the capacities of the two codes (Serpent, ERANOS), and to evaluate the discrepancies between the two calculations, if present. An example for $k_{\text {eff }}$ sensitivity to several responses of selected nuclides $\left({ }^{23} \mathrm{Na},{ }^{235} \mathrm{U}\right.$ and ${ }^{238} \mathrm{U}$ ) are shown in Figs. 9 to 11. From the clear core results it is seen that there are no substantial differences between the results obtained with Serpent and ERANOS. The rest of the examined nuclides are summarized in Tables 1 and 2, the results show a good agreement between the two codes. Some differences are expected when examining the small number values for different isotopes. The overall propagated uncertainties are very consistent, in particular for the important isotopes $\left({ }^{235} \mathrm{U},{ }^{238} \mathrm{U},{ }^{56} \mathrm{Fe}\right.$ and $\left.{ }^{23} \mathrm{Na}\right)$, whose total sensitivity values are in an excellent agreement.

The results for the 3D calculations with ENDF/B-VII.1 library are summarized in Table 3. The results are compared with the JEFF-3.1.1 library in Table 4. Large discrepancies are obtained in the $N, x N$ reaction for the isotopes $-{ }^{23} \mathrm{Na},{ }^{27} \mathrm{Al},{ }^{56} \mathrm{Fe}$ and ${ }^{58} \mathrm{Ni}$. They are mainly due to the low values (both in Serpent and ERANOS calculations) that could be considered as close to zero and then not significant. Additional large errors between the libraries can also be 

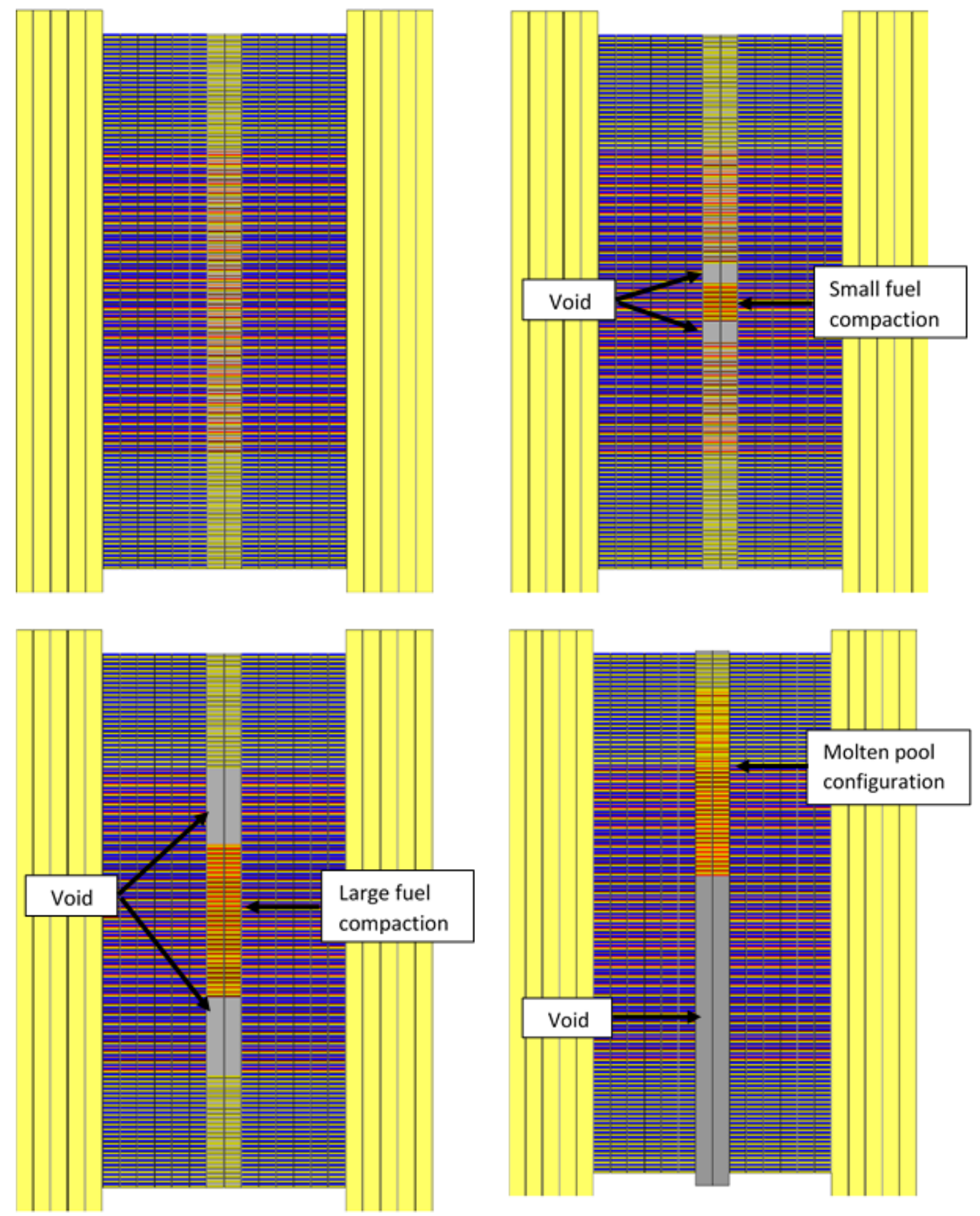

Figure 8: SNEAK-12A fuel slump-in SA scenario stages. 
found in the sensitivities to elastic and inelastic scattering in $\mathrm{C} 0$ and ${ }^{52} \mathrm{Cr}$. This could be attributed to the low material concentrations in the core, which influence the calculation, hence producing small sensitivities.

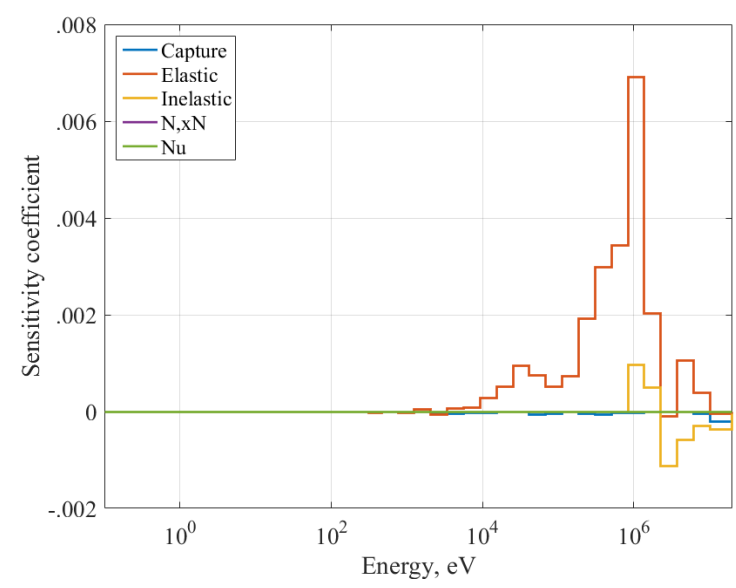

(a) Serpent.

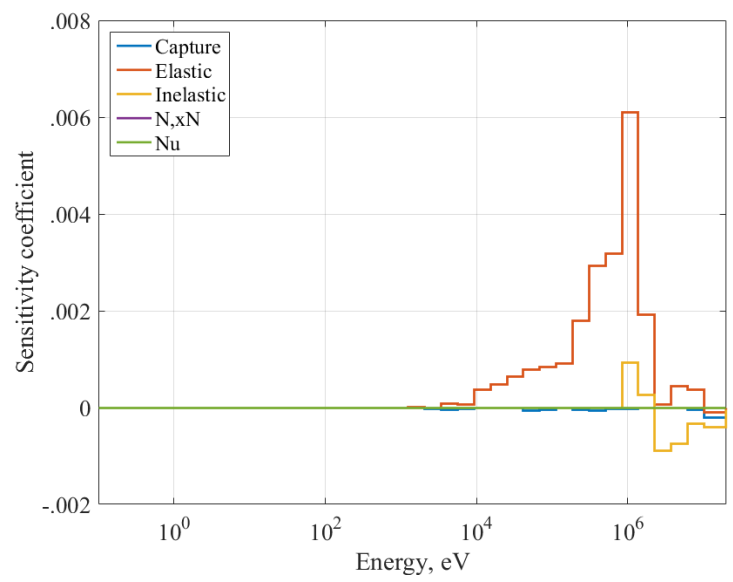

(b) ERANOS.

Figure 9: Clean core effective multiplication factor sensitivity to ${ }^{23} \mathrm{Na}$ cross-sections with JEFF-3.1.1.

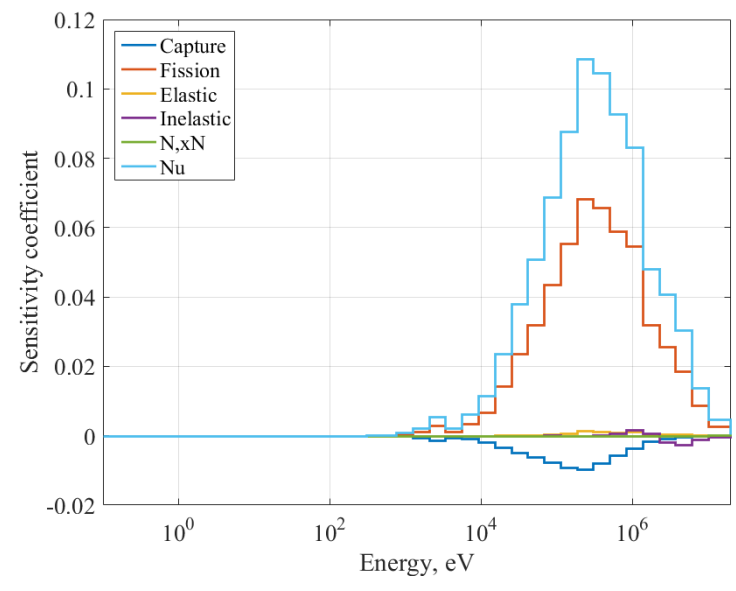

(a) Serpent.

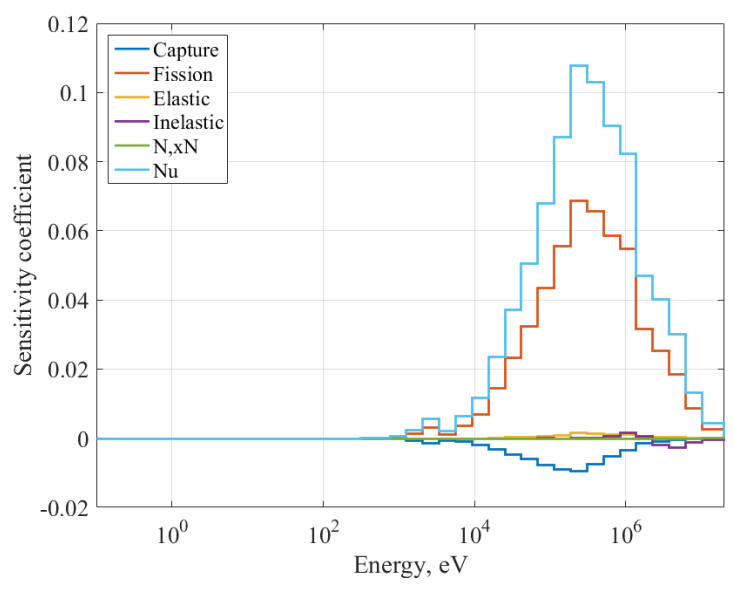

(b) ERANOS.

Figure 10: Clean core effective multiplication factor sensitivity to ${ }^{235} \mathrm{U}$ cross-sections with JEFF-3.1.1.

As discussed in subsection 2.2, there are large differences in sodium cross-sections between ENDF/B-VII.1 and JEFF-3.1.1. Those differences, specially in the inelastic cross section, are seen in Table 4. The associated sensitivity discrepancy reaches about $90 \%$ between the two libraries. The amount of sodium in the core being large, its removal from the core has a significant impact on the reactivity coefficients, and hence on the calculated sensitivity profiles between the two libraries. The distinctive difference in the inelastic scattering cross-section values is a result of analysis of sodium void experiments, the calculation of those analysis were used to scale the JEFF cross-section 


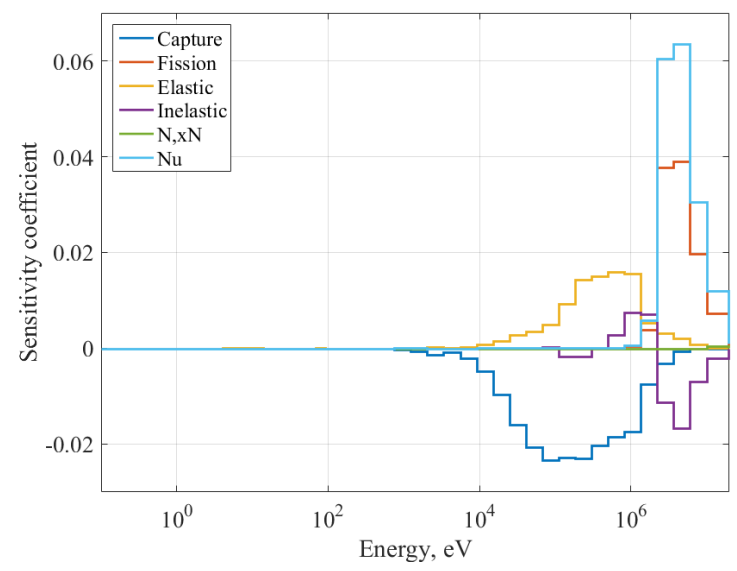

(a) Serpent.

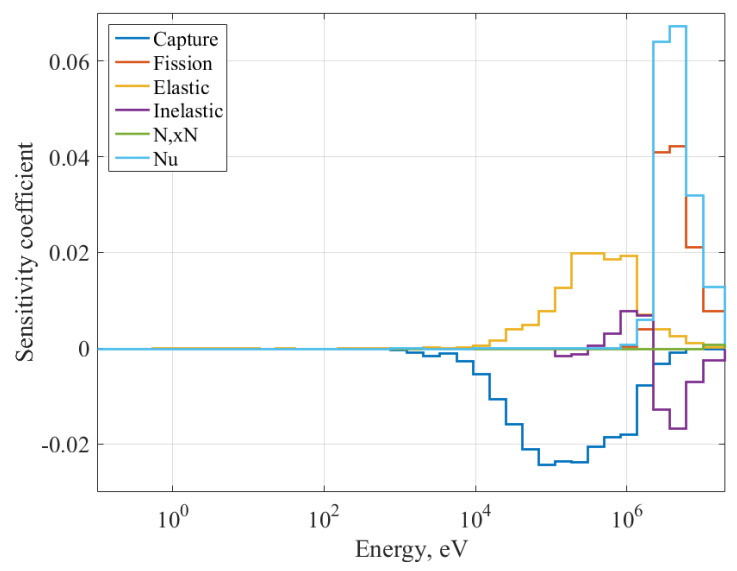

(b) ERANOS.

Figure 11: Clean core effective multiplication factor sensitivity to ${ }^{238} \mathrm{U}$ cross-sections.

Table 1: Sensitivity coefficients calculated by ERANOS v2.4 for R-Z model with JEFF-3.1.1 - Clean core

\begin{tabular}{|c|c|c|c|c|c|c|c|}
\hline Nuclide & Capture & Fission & Elastic & Inelastic & $\mathrm{N}, \mathrm{xN}$ & $\bar{v}$ & Total \\
\hline C- 0 & $<1.0 \mathrm{E}-06$ & & $7.876 \mathrm{E}-05$ & $-1.171 \mathrm{E}-06$ & & & $7.706 \mathrm{E}-05$ \\
\hline O-16 & $-1.364 \mathrm{E}-03$ & & $2.324 \mathrm{E}-02$ & $-1.851 \mathrm{E}-04$ & $<1.0 \mathrm{E}-06$ & & $2.169 \mathrm{E}-02$ \\
\hline $\mathrm{Na}-23$ & $-6.050 \mathrm{E}-04$ & & $2.098 \mathrm{E}-02$ & $-1.168 \mathrm{E}-03$ & $<1.0 \mathrm{E}-06$ & & $1.921 \mathrm{E}-02$ \\
\hline $\mathrm{Al}-27$ & $<1.0 \mathrm{E}-06$ & & 7.749E-06 & $-1.402 \mathrm{E}-06$ & $<1.0 \mathrm{E}-06$ & & $5.861 \mathrm{E}-06$ \\
\hline $\mathrm{Cr}-52$ & $-2.310 \mathrm{E}-04$ & & $1.763 \mathrm{E}-03$ & $-5.025 \mathrm{E}-04$ & $<1.0 \mathrm{E}-06$ & & $1.030 \mathrm{E}-03$ \\
\hline $\mathrm{Fe}-56$ & $-2.267 \mathrm{E}-03$ & & $1.247 \mathrm{E}-02$ & $-4.333 \mathrm{E}-03$ & $<1.0 \mathrm{E}-06$ & & $5.874 \mathrm{E}-03$ \\
\hline $\mathrm{Ni}-58$ & $-2.492 \mathrm{E}-03$ & & $3.853 \mathrm{E}-03$ & $-5.582 \mathrm{E}-04$ & $<1.0 \mathrm{E}-06$ & & 8.027E-04 \\
\hline $\mathrm{U}-235$ & $-6.363 \mathrm{E}-02$ & $5.224 \mathrm{E}-01$ & $9.822 \mathrm{E}-03$ & $-1.974 \mathrm{E}-03$ & $1.683 \mathrm{E}-04$ & $8.158 \mathrm{E}-01$ & $1.283 \mathrm{E}+00$ \\
\hline $\mathrm{U}-238$ & $-1.989 \mathrm{E}-01$ & $1.176 \mathrm{E}-01$ & $1.257 \mathrm{E}-01$ & $-2.291 \mathrm{E}-02$ & $8.644 \mathrm{E}-04$ & $1.842 \mathrm{E}-01$ & $2.066 \mathrm{E}-01$ \\
\hline Total & $-2.695 \mathrm{E}-01$ & $6.400 \mathrm{E}-01$ & $1.979 \mathrm{E}-01$ & $-3.163 \mathrm{E}-02$ & $1.033 \mathrm{E}-03$ & $1.000 \mathrm{E}+00$ & $1.538 \mathrm{E}+00$ \\
\hline
\end{tabular}


Table 2: Sensitivity coefficients calculated by Serpent for 3D model with JEFF-3.1.1 - Clean core

\begin{tabular}{|c|c|c|c|c|c|c|c|}
\hline Nuclide & Capture & Fission & Elastic & Inelastic & $\mathrm{N}, \mathrm{xN}$ & $\bar{v}$ & Total \\
\hline $\mathrm{C}-0$ & $<1.0 \mathrm{E}-06$ & & $6.380 \mathrm{E}-05$ & $<1.0 \mathrm{E}-06$ & & & $6.198 \mathrm{E}-05$ \\
\hline O-16 & $-1.082 \mathrm{E}-03$ & & $2.329 \mathrm{E}-02$ & $-2.145 \mathrm{E}-04$ & & & 2.199E-02 \\
\hline $\mathrm{Na}-23$ & $-6.610 \mathrm{E}-04$ & & $2.255 \mathrm{E}-02$ & $-9.267 \mathrm{E}-04$ & $<1.0 \mathrm{E}-06$ & & $2.096 \mathrm{E}-02$ \\
\hline $\mathrm{Al}-27$ & $-4.783 \mathrm{E}-05$ & & $1.249 \mathrm{E}-04$ & $-1.146 \mathrm{E}-04$ & $<1.0 \mathrm{E}-06$ & & $-3.753 \mathrm{E}-05$ \\
\hline $\mathrm{Cr}-52$ & $-5.230 \mathrm{E}-04$ & & 3.613E-03 & $-1.120 \mathrm{E}-03$ & $<1.0 \mathrm{E}-06$ & & $1.970 \mathrm{E}-03$ \\
\hline $\mathrm{Fe}-56$ & $-2.400 \mathrm{E}-03$ & & $1.253 \mathrm{E}-02$ & $-3.982 \mathrm{E}-03$ & $<1.0 \mathrm{E}-06$ & & $6.147 \mathrm{E}-03$ \\
\hline $\mathrm{Ni}-58$ & $-2.575 \mathrm{E}-03$ & & 3.634E-03 & $-5.912 \mathrm{E}-04$ & $<1.0 \mathrm{E}-06$ & & 4.678E-04 \\
\hline U-235 & $-6.618 \mathrm{E}-02$ & 5.204E-01 & 7.336E-03 & $-2.412 \mathrm{E}-03$ & $1.579 \mathrm{E}-04$ & $8.258 \mathrm{E}-01$ & $1.285 \mathrm{E}+00$ \\
\hline U-238 & $-1.928 \mathrm{E}-01$ & $1.089 \mathrm{E}-01$ & $9.611 \mathrm{E}-02$ & $-2.312 \mathrm{E}-02$ & $5.811 \mathrm{E}-04$ & $1.742 \mathrm{E}-01$ & 1.639E-01 \\
\hline Total & $-2.663 \mathrm{E}-01$ & $6.293 \mathrm{E}-01$ & $1.693 \mathrm{E}-01$ & $-3.248 \mathrm{E}-02$ & 7.383E-04 & $1.000 \mathrm{E}+00$ & $1.501 \mathrm{E}+00$ \\
\hline
\end{tabular}

Table 3: Sensitivity coefficients calculated by Serpent for 3D model with ENDF/B-VII.1 - Clean core

\begin{tabular}{|c|c|c|c|c|c|c|c|}
\hline Nuclide & Capture & Fission & Elastic & Inelastic & $\mathrm{N}, \mathrm{xN}$ & $\bar{v}$ & Total \\
\hline $\mathrm{C}-0$ & $<1.0 \mathrm{E}-06$ & & $5.503 \mathrm{E}-05$ & $-1.408 \mathrm{E}-06$ & & & $5.275 \mathrm{E}-05$ \\
\hline O-16 & $-9.886 \mathrm{E}-04$ & & $2.248 \mathrm{E}-02$ & $-2.243 \mathrm{E}-04$ & & & 2.127E-02 \\
\hline $\mathrm{Na}-23$ & $-7.167 \mathrm{E}-04$ & & $2.156 \mathrm{E}-02$ & $-1.774 \mathrm{E}-03$ & $<1.0 \mathrm{E}-06$ & & 1.907E-02 \\
\hline $\mathrm{Al}-27$ & $-4.762 \mathrm{E}-05$ & & $1.150 \mathrm{E}-04$ & $-1.058 \mathrm{E}-04$ & & & $-3.842 \mathrm{E}-05$ \\
\hline Cr-52 & $-5.257 \mathrm{E}-04$ & & $4.411 \mathrm{E}-03$ & $-1.349 \mathrm{E}-03$ & $<1.0 \mathrm{E}-06$ & & $2.536 \mathrm{E}-03$ \\
\hline Fe-56 & $-2.540 \mathrm{E}-03$ & & $1.286 \mathrm{E}-02$ & $-4.107 \mathrm{E}-03$ & $<1.0 \mathrm{E}-06$ & & $6.212 \mathrm{E}-03$ \\
\hline $\mathrm{Ni}-58$ & $-2.624 \mathrm{E}-03$ & & 4.095E-03 & $-6.068 \mathrm{E}-04$ & $<1.0 \mathrm{E}-06$ & & 8.642E-04 \\
\hline U-235 & $-6.601 \mathrm{E}-02$ & $5.210 \mathrm{E}-01$ & 7.449E-03 & $-2.722 \mathrm{E}-03$ & $1.662 \mathrm{E}-04$ & $8.242 \mathrm{E}-01$ & $1.284 \mathrm{E}+00$ \\
\hline U-238 & $-1.911 \mathrm{E}-01$ & $1.095 \mathrm{E}-01$ & $9.427 \mathrm{E}-02$ & $-2.074 \mathrm{E}-02$ & $6.235 \mathrm{E}-04$ & $1.758 \mathrm{E}-01$ & $1.684 \mathrm{E}-01$ \\
\hline Total & $-2.646 \mathrm{E}-01$ & $6.305 \mathrm{E}-01$ & $1.673 \mathrm{E}-01$ & $-3.163 \mathrm{E}-02$ & $7.884 \mathrm{E}-04$ & $1.000 \mathrm{E}+00$ & $1.502 \mathrm{E}+00$ \\
\hline
\end{tabular}


Table 4: Sensitivity coefficient relative error between JEFF-3.1.1 and ENDF/B-VII.1 for 3D calculations - Clean core

\begin{tabular}{lccccccc}
\hline Nuclide & Capture & Fission & Elastic & Inelastic & $\mathrm{N}, \mathrm{xN}$ & $\bar{v}$ & Total \\
\hline $\mathrm{C}-0$ & $-5.63 \%$ & & $-13.75 \%$ & $57.30 \%$ & & & $-14.89 \%$ \\
$\mathrm{O}-16$ & $-8.63 \%$ & & $-3.48 \%$ & $4.57 \%$ & & & $-3.30 \%$ \\
$\mathrm{Na}-23$ & $8.43 \%$ & & $-4.39 \%$ & $91.43 \%$ & $-168.46 \%$ & & $-9.03 \%$ \\
$\mathrm{Al}-27$ & $-0.44 \%$ & & $-7.93 \%$ & $-7.68 \%$ & $-100.00 \%$ & & $2.38 \%$ \\
$\mathrm{Cr}-52$ & $0.52 \%$ & & $22.09 \%$ & $20.45 \%$ & $-370.58 \%$ & & $28.69 \%$ \\
$\mathrm{Fe}-56$ & $5.83 \%$ & & $2.63 \%$ & $3.14 \%$ & $12.99 \%$ & & $1.06 \%$ \\
$\mathrm{Ni}-58$ & $1.90 \%$ & & $12.69 \%$ & $2.64 \%$ & $-98.56 \%$ & & $84.72 \%$ \\
$\mathrm{U}-235$ & $-0.26 \%$ & $0.12 \%$ & $1.54 \%$ & $12.85 \%$ & $5.26 \%$ & $-0.19 \%$ & $-0.08 \%$ \\
$\mathrm{U}-238$ & $-0.88 \%$ & $0.55 \%$ & $-1.91 \%$ & $-10.29 \%$ & $7.30 \%$ & $0.92 \%$ & $2.74 \%$ \\
\hline Total & $-0.64 \%$ & $0.19 \%$ & $-1.16 \%$ & $-2.62 \%$ & $6.80 \%$ & $0.00 \%$ & $0.12 \%$ \\
\hline
\end{tabular}

libraries ( Fort et al. (2003)).

In order to translate the clear criticality experiment sensitivity profiles into uncertainties values, it is necessary to assess the level of uncertainties of the multigroup cross-section set used, through the variances and covariances. This is done using the COMAC covariance matrix. The results of the uncertainties associated with the different responses of the examined isotopes are summarized in Fig. 12 and in Tables 5 and 6. The agreement between the two codes is good, as the main sensitivity profiles were in excellent agreement.

From Fig. 12 can be seen that the reactions with the highest propagated uncertainties are capture and fission of ${ }^{235} \mathrm{U}$ and ${ }^{238} \mathrm{U}$. The correlation matrix and the uncertainty vector for capture reactions in ${ }^{235} \mathrm{U}$ and ${ }^{238} \mathrm{U}$ are shown in Fig. 13 and 14 respectively. The uncertainty vectors for those isotopes are high in the fast energy region, which contributes to the high uncertainty values. Compared to other studied fast systems ((Palmiotti et al., 2015; Salvatores et al., 2014)), the propagated uncertainties are quite large, especially for an uranium system. However, SNEAK-12 lattices being fuelled with highly dense metal $\mathrm{U}$, the density effect directly affects the sensitivity profile. Therefore, the high uranium loading contributes strongly to the final uncertainty value both in capture and fission reaction. On the other hand the $\bar{v}$ reaction has the highest sensitivity value contributes very little to the total propagated uncertainty, which is a result of a very low uncertainty values in the covariance data.The total propagated uncertainties from all the investigated isotopes cross-sections are summarized in Table 7.

\subsection{Reactivity changes sensitivities in molten pool configurations}

The results in this section illustrate the sensitivity of the cross-section data on the reactivity variation due to sodium and material relocation in molten pool configurations of the SNEAK-12A core. The changes of some of the presented 


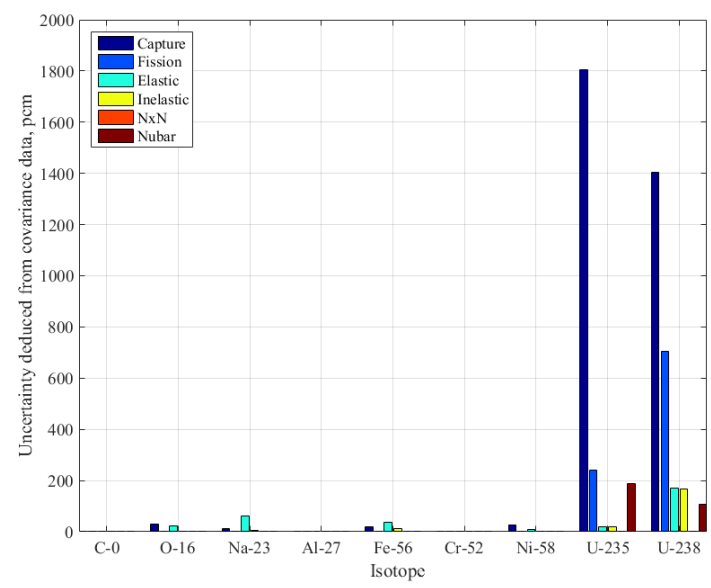

(a) Serpent.

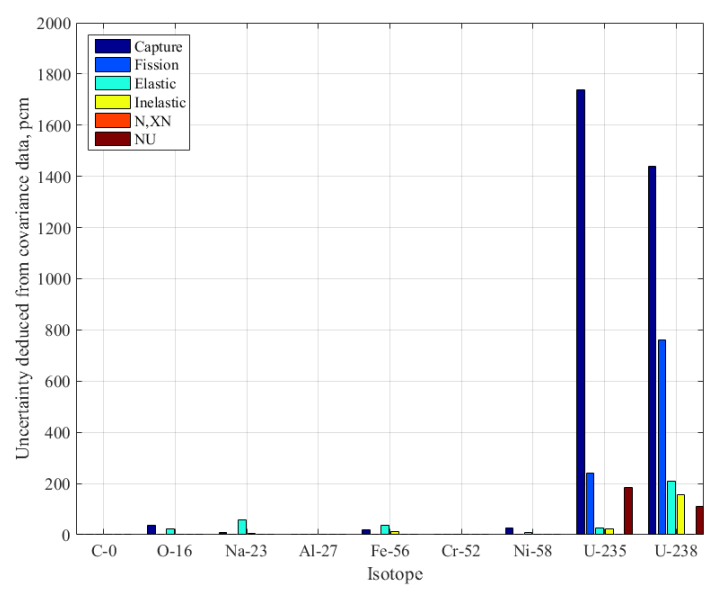

(b) ERANOS

Figure 12: Comparison of propagated cross-section uncertainty values for selected isotopes of clean core configuration of SNEAK-12A.

Table 5: Uncertainty values per isotope for Serpent-COMAC calc.

\begin{tabular}{lcccccc}
\hline & Capture & Fission & Elastic & Inelastic & $\mathrm{N}, \mathrm{xN}$ & $\bar{v}$ \\
\hline $\mathrm{C} 0$ & $<1.0 \mathrm{E}-06$ & $<1.0 \mathrm{E}-06$ & $<1.0 \mathrm{E}-06$ & & & \\
$\mathrm{O} 16$ & $2.914 \mathrm{E}-04$ & $2.221 \mathrm{E}-04$ & $1.439 \mathrm{E}-05$ & & & \\
$\mathrm{Na} 23$ & $1.060 \mathrm{E}-04$ & $6.161 \mathrm{E}-04$ & $6.035 \mathrm{E}-05$ & $<1.0 \mathrm{E}-06$ & & \\
$\mathrm{~A} 27$ & $7.817 \mathrm{E}-06$ & $3.439 \mathrm{E}-05$ & $1.875 \mathrm{E}-05$ & $<1.0 \mathrm{E}-06$ & & \\
$\mathrm{Cr} 52$ & $3.235 \mathrm{E}-05$ & $1.325 \mathrm{E}-05$ & $1.430 \mathrm{E}-05$ & $<1.0 \mathrm{E}-06$ & & \\
$\mathrm{Fe} 56$ & $2.088 \mathrm{E}-04$ & $3.749 \mathrm{E}-04$ & $1.116 \mathrm{E}-04$ & $<1.0 \mathrm{E}-06$ & & \\
$\mathrm{Ni} 58$ & $2.808 \mathrm{E}-04$ & $7.090 \mathrm{E}-05$ & $1.213 \mathrm{E}-05$ & $<1.0 \mathrm{E}-06$ & & \\
$\mathrm{U} 235$ & $1.806 \mathrm{E}-02$ & $2.395 \mathrm{E}-03$ & $1.986 \mathrm{E}-04$ & $2.002 \mathrm{E}-04$ & $6.371 \mathrm{E}-06$ & $1.880 \mathrm{E}-03$ \\
$\mathrm{U} 238$ & $1.404 \mathrm{E}-02$ & $7.035 \mathrm{E}-03$ & $1.696 \mathrm{E}-03$ & $1.658 \mathrm{E}-03$ & $3.232 \mathrm{E}-05$ & $1.055 \mathrm{E}-03$ \\
\hline
\end{tabular}


Table 6: Uncertainty values per isotope for ERANOS-COMAC calc.

\begin{tabular}{lcccccc}
\hline & Capture & Fission & Elastic & Inelastic & $\mathrm{N}, \mathrm{xN}$ & $\bar{v}$ \\
\hline $\mathrm{C} 0$ & $<1.0 \mathrm{E}-06$ & $<1.0 \mathrm{E}-06$ & $<1.0 \mathrm{E}-06$ & & & \\
$\mathrm{O} 16$ & $<1.0 \mathrm{E}-06$ & $2.242 \mathrm{E}-04$ & $1.223 \mathrm{E}-05$ & & & \\
$\mathrm{~N} 233$ & $9.726 \mathrm{E}-05$ & $5.843 \mathrm{E}-04$ & $6.487 \mathrm{E}-05$ & & & \\
$\mathrm{~A} 127$ & $<1.0 \mathrm{E}-06$ & $<1.0 \mathrm{E}-06$ & $<1.0 \mathrm{E}-06$ & & & \\
$\mathrm{C} 52$ & $1.403 \mathrm{E}-05$ & $5.451 \mathrm{E}-06$ & $6.482 \mathrm{E}-06$ & & & \\
$\mathrm{Fe} 56$ & $1.969 \mathrm{E}-04$ & $3.698 \mathrm{E}-04$ & $1.165 \mathrm{E}-04$ & & & \\
$\mathrm{~N} 158$ & $2.742 \mathrm{E}-04$ & $7.847 \mathrm{E}-05$ & $1.118 \mathrm{E}-05$ & & & \\
$\mathrm{U} 235$ & $1.739 \mathrm{E}-02$ & $2.407 \mathrm{E}-03$ & $2.592 \mathrm{E}-04$ & $2.126 \mathrm{E}-04$ & $<1.0 \mathrm{E}-06$ & $1.856 \mathrm{E}-03$ \\
$\mathrm{U} 238$ & $1.438 \mathrm{E}-02$ & $7.595 \mathrm{E}-03$ & $2.108 \mathrm{E}-03$ & $1.567 \mathrm{E}-03$ & $<1.0 \mathrm{E}-06$ & $1.116 \mathrm{E}-03$ \\
\hline
\end{tabular}
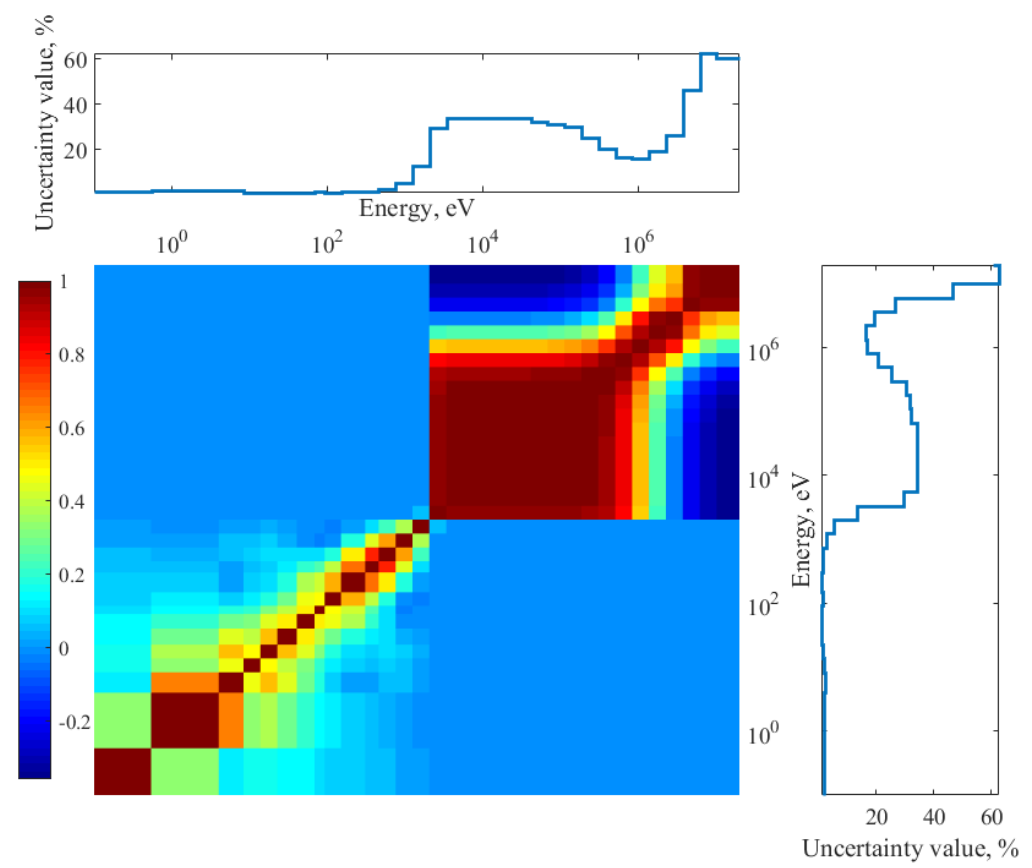

Figure 13: Covariance data for capture in ${ }^{235} \mathrm{U}$ taken from the COMAC evaluation 


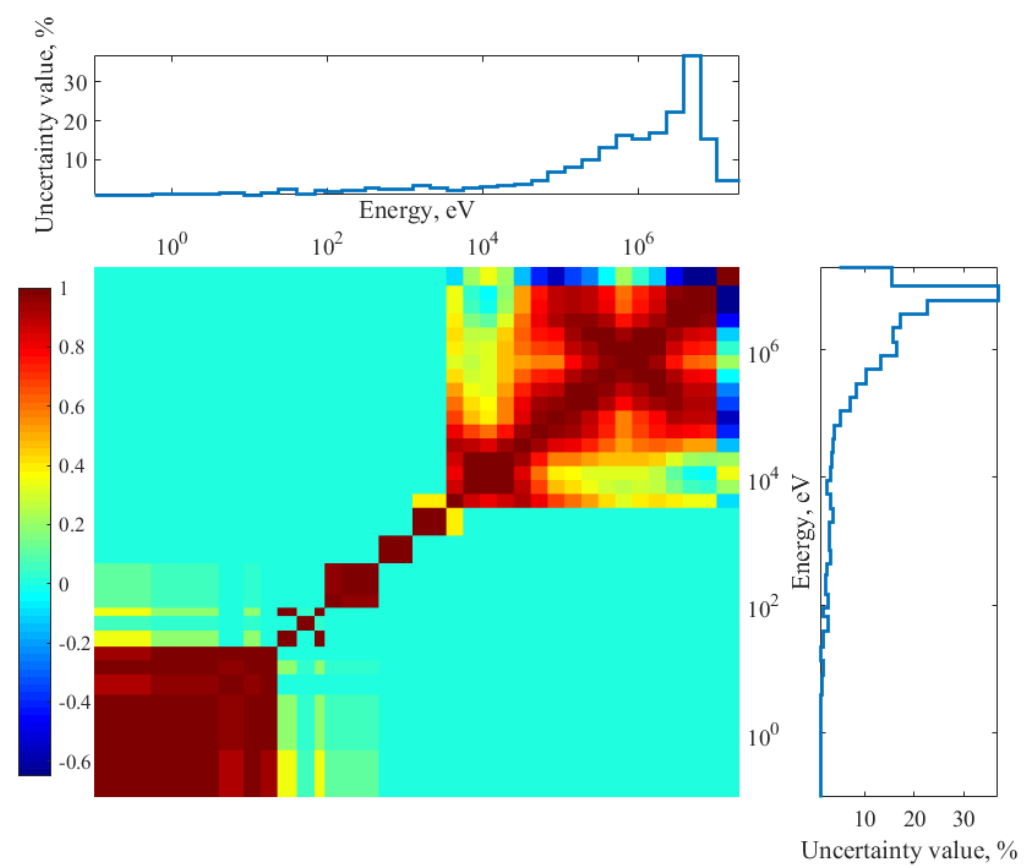

Figure 14: Covariance data for capture in ${ }^{238} \mathrm{U}$ taken from the COMAC evaluation

Table 7: Summary of total uncertainty values for the SNEAK-12A clear core configuration in pcm

Serpent-COMAC ERANOS-COMAC

\begin{tabular}{lll}
\hline Correlated reactions only & 2430 & 2420 \\
Cross-correlated reaction included & 2260 & 2230 \\
\hline
\end{tabular}


results are small, the results in this section are presented in term of $\Delta \rho S(\Delta \rho, \Sigma(n, r))$, which can be expressed directly in $p c m / \%$ as it gives the variation of the soidum void worth caused by $1 \%$ variation in the cross-section.

The most prominent sensitivity profiles for the reactivity changes for the SNEAK-12A molten pool configurations are given in Figs. 15 to 19, and for ERANOS in Figs. 20 to 24. The results show quite a good agreement between ERANOS and Serpent for the different isotopes in standard 33-group energy mesh. Fig. 15 and Fig. 20 show the Na-void sensitivity to the ${ }^{23} \mathrm{Na}$ elastic and inelastic cross sections obtained from Serpent and ERANOS calculations respectively. As it can be seen for small molten pool configurations (4 to 12 affected elements), there is no large sensitivity to sodium cross section. However, as the molten pool grows, the effect becomes more substantial. The individual sensitivities remains rather small $(<200 \mathrm{pcm} / \%$ at the largest configurations), but the uncertainties, which will be described later, reach higher levels probably would be high.

Figs. 18 and 19 and Figs. 23 and 24 show the Na-void sensitivity profiles to the capture and fission of ${ }^{235} \mathrm{U}$ and ${ }^{238} \mathrm{U}$ from Serpent and ERANOS calculation respectively. The sensitivity to fission reaction for ${ }^{238} \mathrm{U}$, a nuclide with fission threshold, relates mainly to the amount of the isotope in the core, and remains low with high sensitivity levels at higher energies. The Na-void sensitivities to ${ }^{235} \mathrm{U}$ fission and ${ }^{238} \mathrm{U}$ capture are quite high $(>500 \mathrm{pcm} / \%$ for some individual energy groups), but those reactions have low uncertainties, as they are well modeled and studied.

From the results presented there are two notable behaviors. The first regards the elastic scattering of oxygen and sodium. The reactions are seem to go in oppose directions, while the sodium is negative (Fig. 15 and 20) the oxygen is positive (Fig. 16 and 21). This is linked to the cross-section behavior at around neutron energy of $1 \mathrm{MeV}$ (Fig.25). Around this energy point the oxygen cross-section is has a rising tendency while the sodium has the opposite behavior. The second behavior is linked to the fission sensitivity profile of ${ }^{235} \mathrm{U}$ (Figs. 18 and 23, the fission senstivity profile is changing signs as the energy getting lower. This kind of behavior is a result of the spectrum hardening in the larger molten pool configuration, as shown in Fig. 26 for two edge configurations.

The calculated reactivirty change values for molten pool growth are given in Table 8. The uncertainties for the reactivity changes between the different stages are summarized in Table. 9, and also shown in Fig. 27. The highest contributions to the total uncertainties analysis arrives from the uranium isotopes. They are are given in Fig. 28. The most significant contributor is the capture in both ${ }^{235} \mathrm{U}$ and ${ }^{238} \mathrm{U}$ isotopes, as discussed in the uncertainty analysis of the clean core configuration (mainly addressed to the high uncertainties in the covariance data Fig 13 and 14). It should be noted that the general trend remains the same, with different magnitudes, with respect to the clean criticality experiment. The magnitude of the uncertainties is large for all the molten pool cases, this indicates on a cross section adjustment requirement for some of the examined isotopes.

The propagated uncertainties contribution from the sodium voiding remains small. This result is a direct impact of the inclusion of sodium voiding experiments in the new nuclear data evaluation of ${ }^{23} \mathrm{Na}$ in the JEFF3.1.1 library, leading to very low uncertainty vectors in the elastic and inelastic covariance data in Fig. 29 and 30. However, if neglecting the high contributions of the uranium isotopes to the total uncertainty, the sodium is the highest contributor to the total uncertainty. 

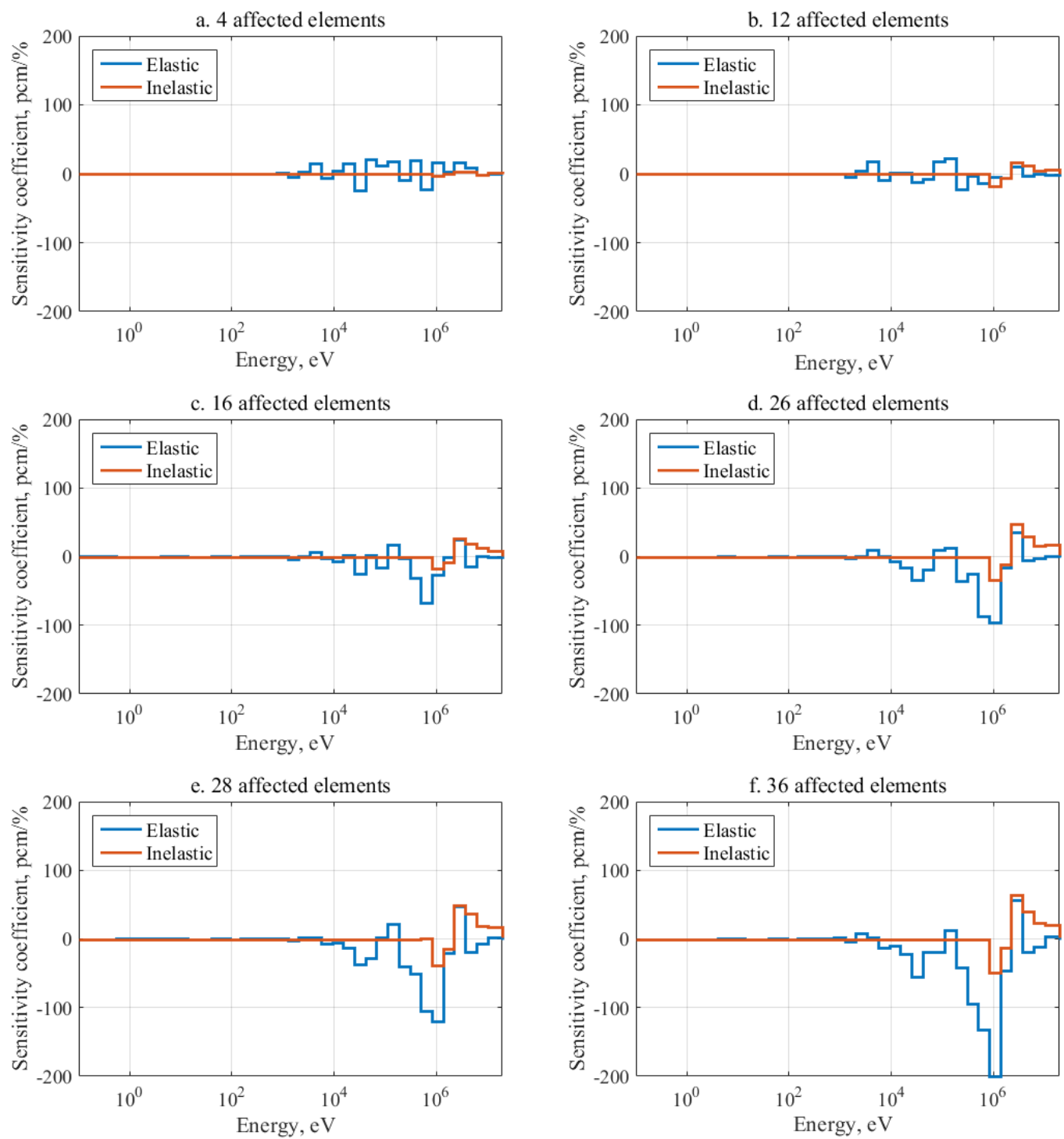

Figure 15: 33 group Na void sensitivity to ${ }^{23} \mathrm{Na}$ cross section for different stages of molten pool configurations from Serpent calculations. 
a. 4 affected elements

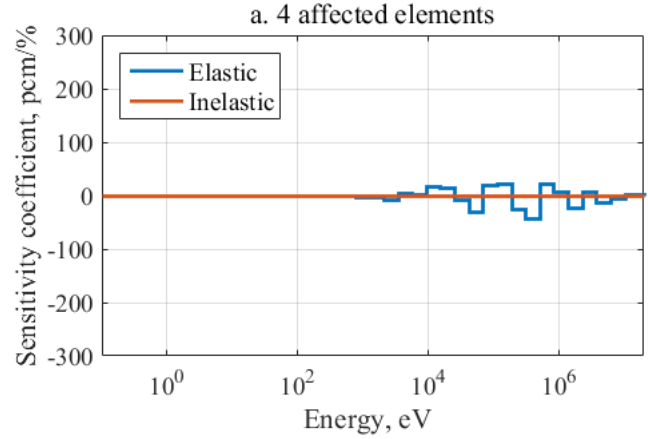

c. 16 affected elements

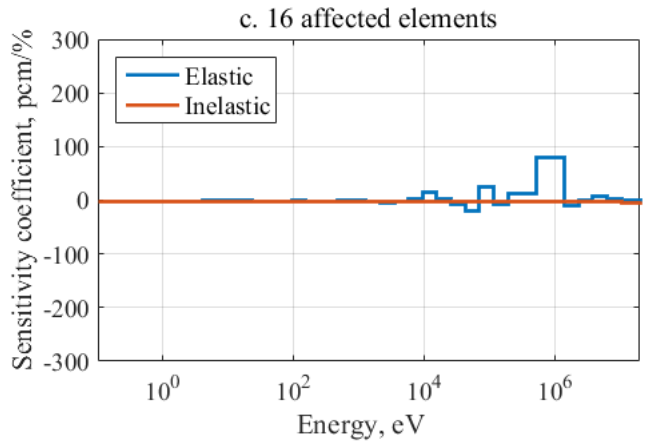

e. 28 affected elements

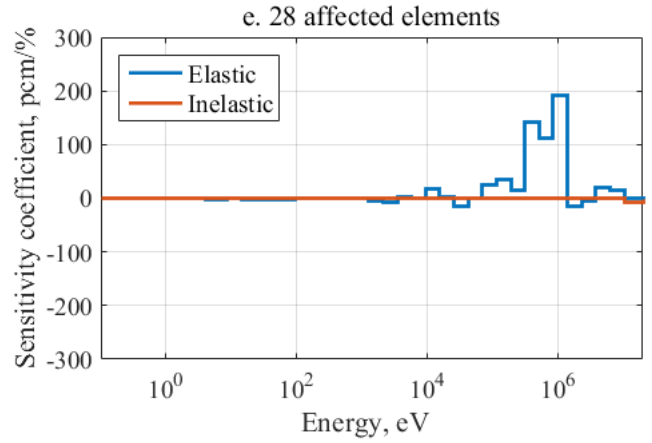

b. 12 affected elements

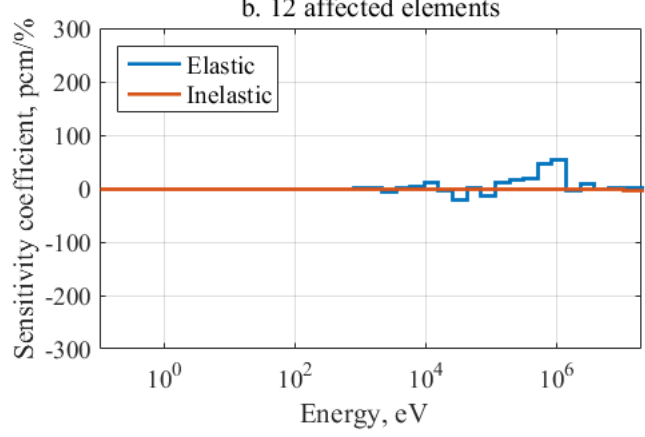

d. 26 affected elements

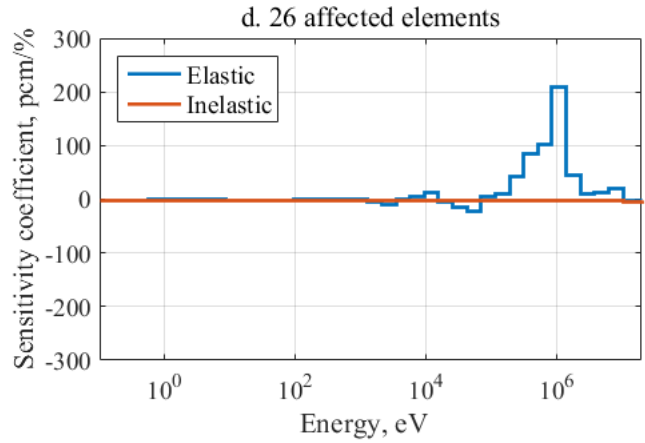

f. 36 affected elements

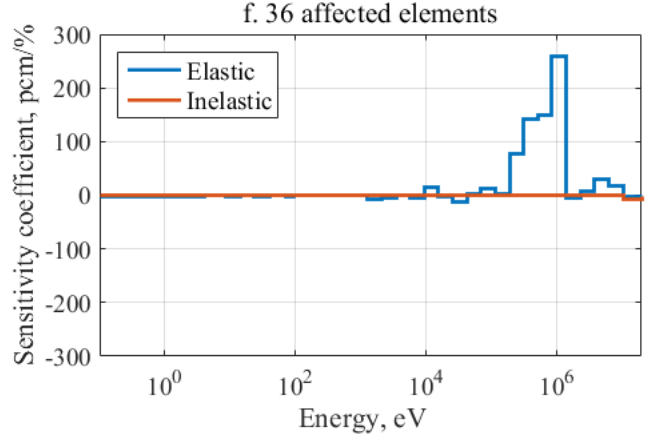

Figure 16: 33 group Na void sensitivity to ${ }^{16} \mathrm{O}$ cross section for different stages of molten pool configurations from Serpent calculations. 

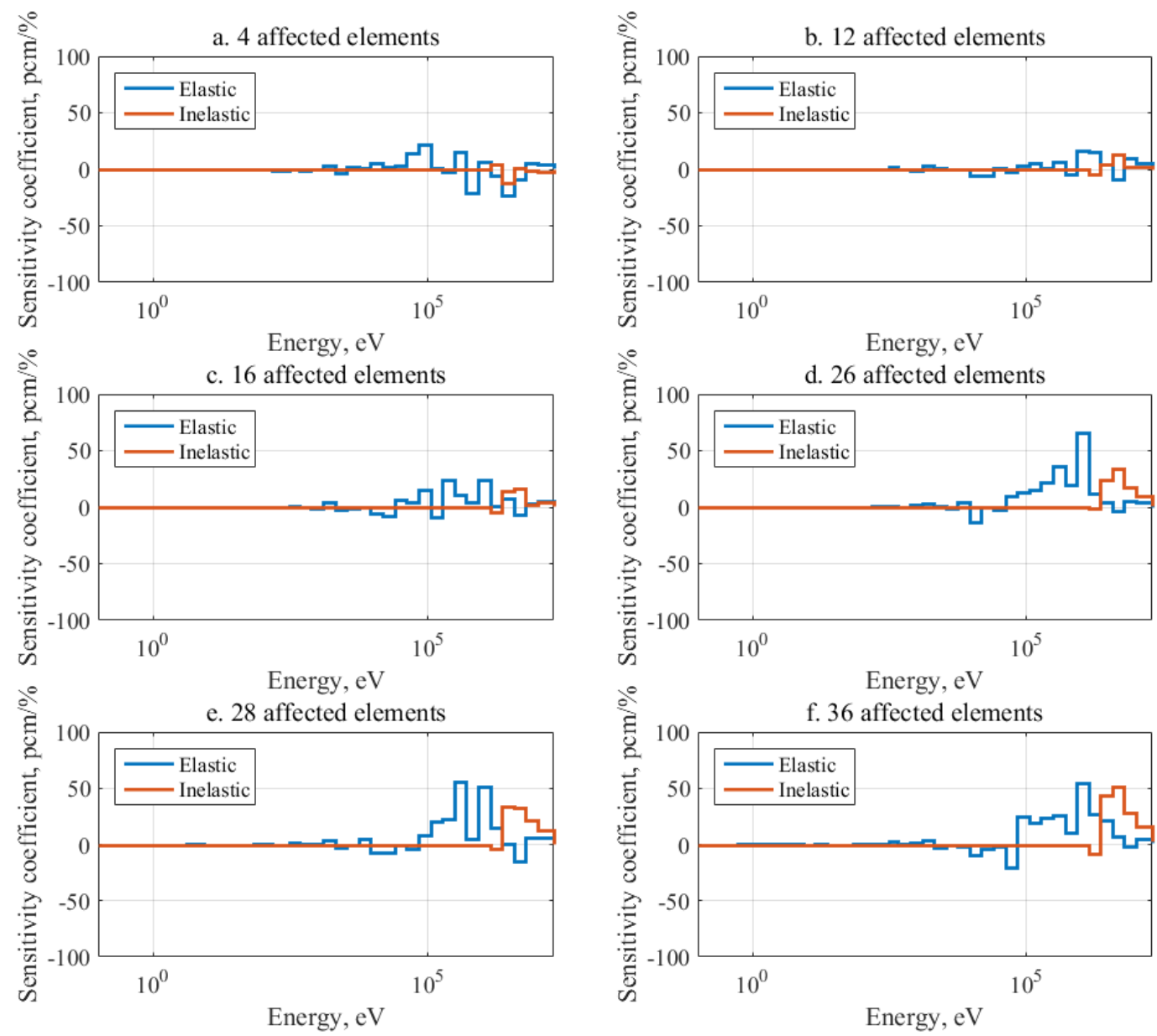

Figure 17: 33 group Na void sensitivity to ${ }^{56} \mathrm{Fe}$ cross section for different stages of molten pool configurations from Serpent calculations.

Table 8: Reactivity changes between different molten pool configurations obtained from Serpent and ERANOS calculations, in pcm.

\begin{tabular}{lcc}
\hline Affected elem. & Serpent2 & ERANOS(R-Z) \\
\hline 0 & 0 & 0 \\
4 & -64.66 & -65.1 \\
12 & -212.20 & -216.35 \\
16 & -162.30 & - \\
26 & -124.42 & - \\
28 & 63.58 & 78.34 \\
36 & 888.69 & - \\
\hline
\end{tabular}



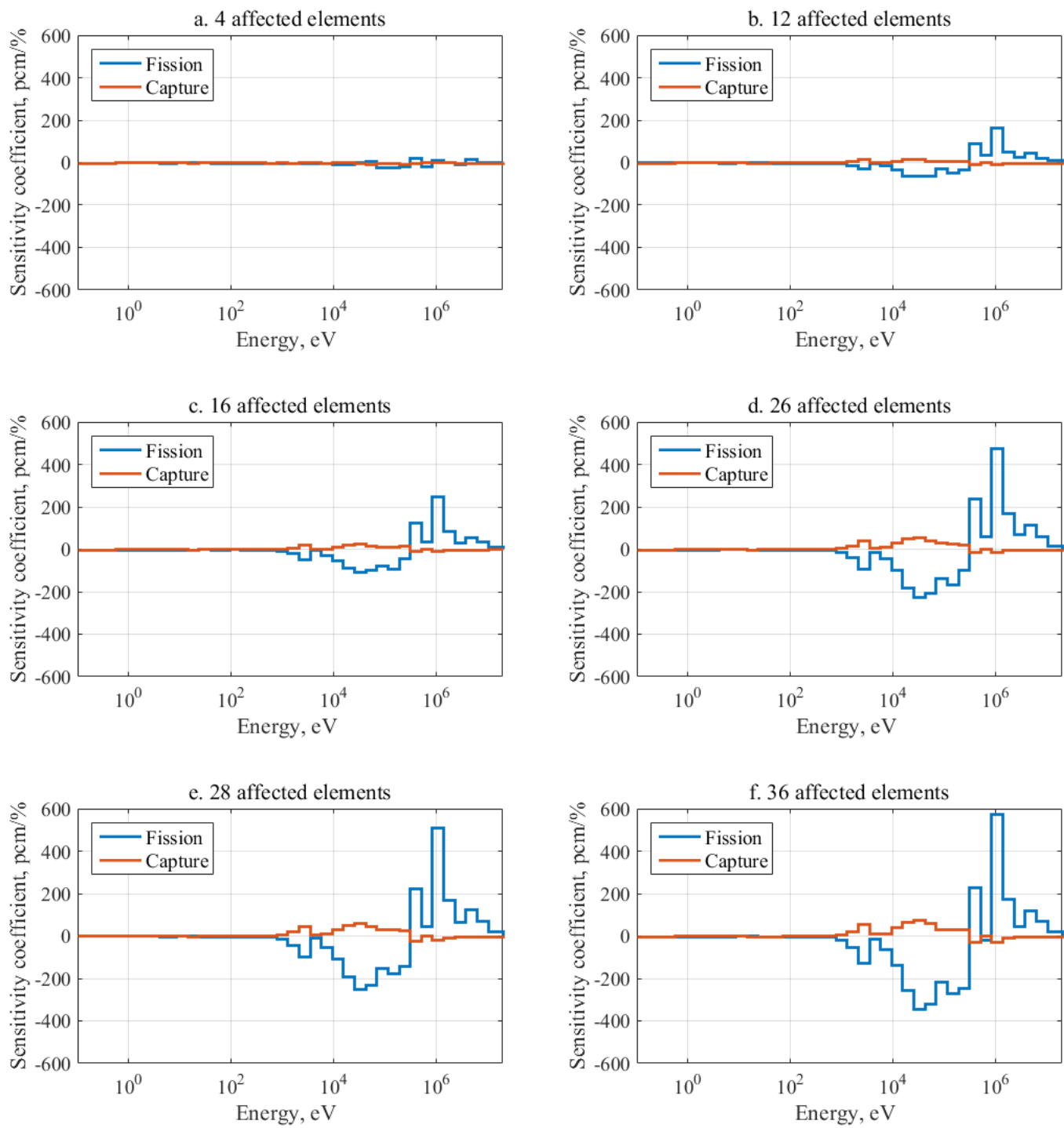

Figure 18: 33 group Na void sensitivity to ${ }^{235} \mathrm{U}$ cross section for different stages of molten pool configurations from Serpent calculations. 

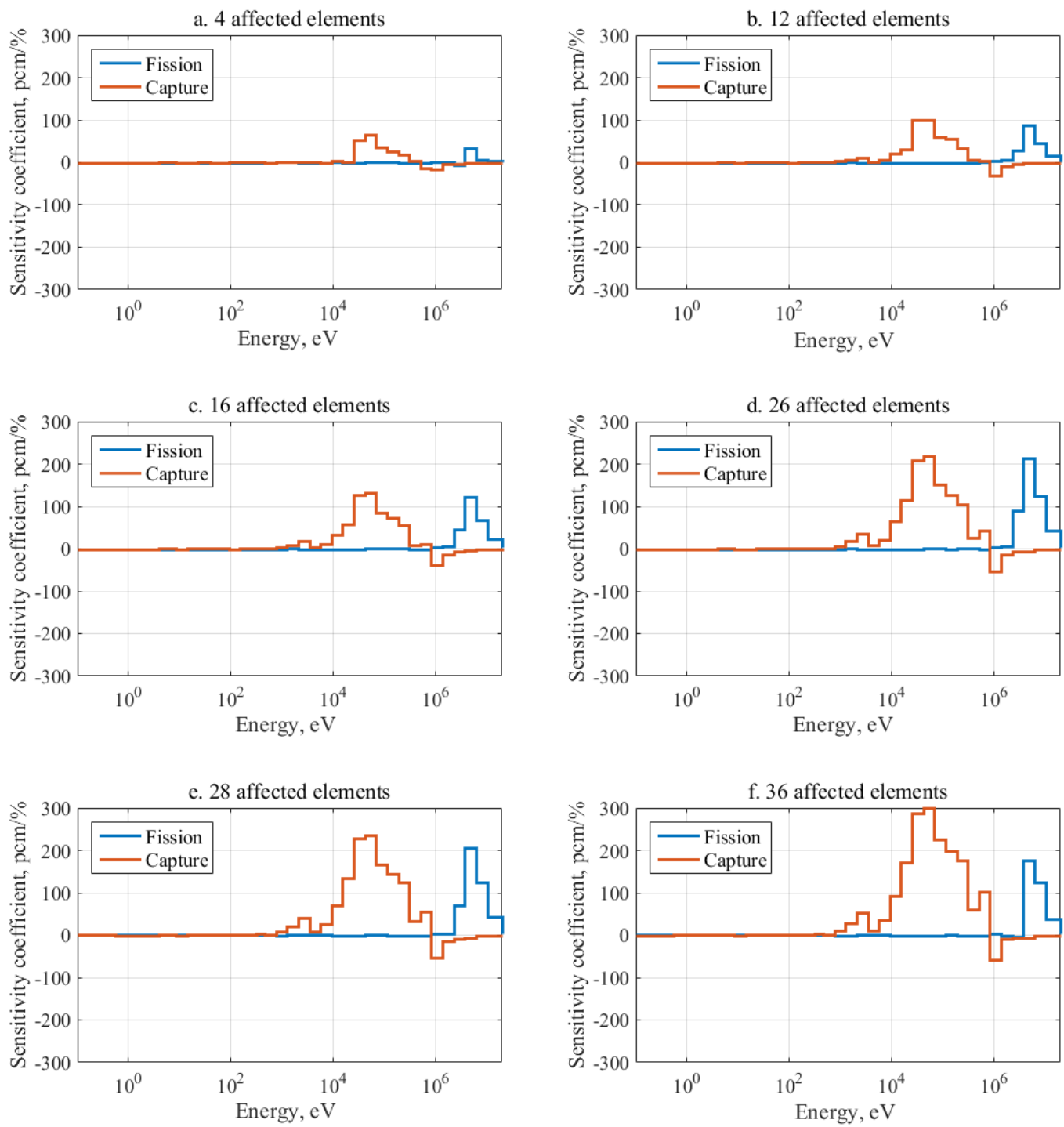

Figure 19: 33 group Na void sensitivity to ${ }^{238} \mathrm{U}$ cross section for different stages of molten pool configurations from Serpent calculations. 

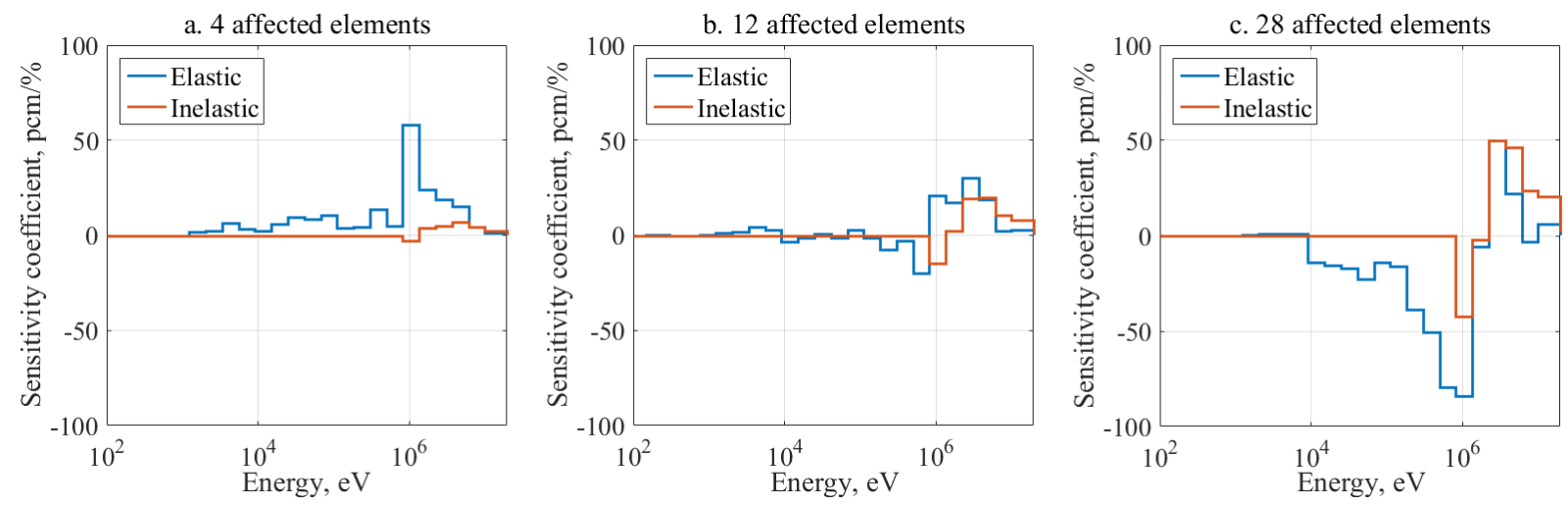

Figure 20: 33 group $\mathrm{Na}$ void sensitivity to ${ }^{23} \mathrm{Na}$ cross section for different stages of molten pool configurations from ERANOS calculations.
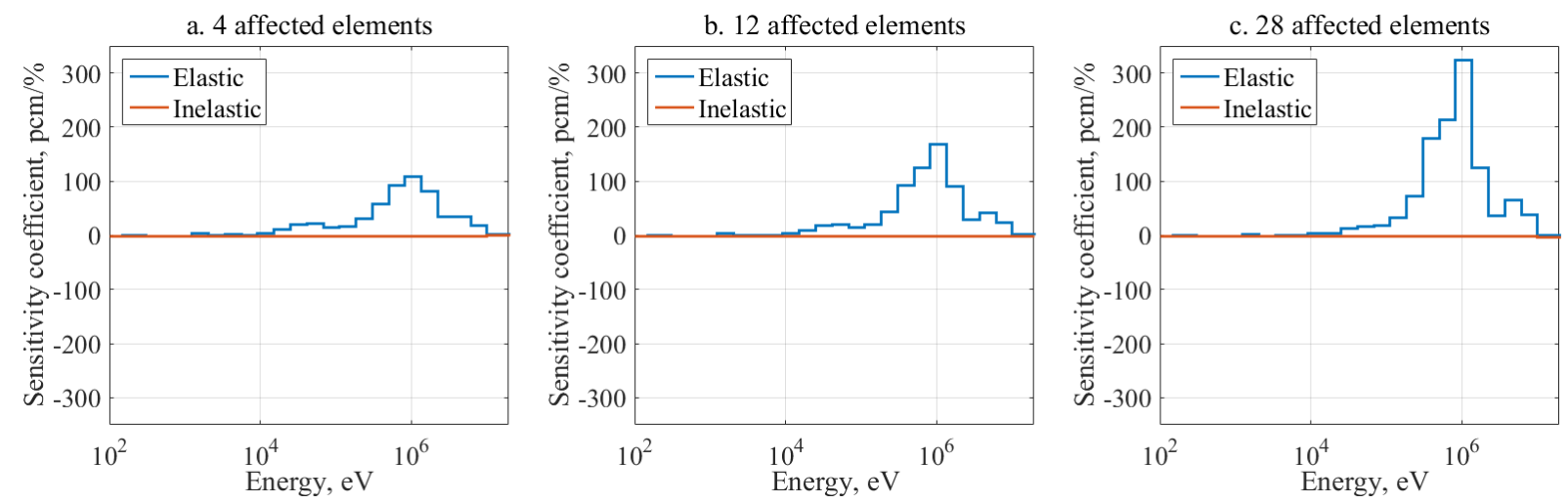

Figure 21: 33 group Na void sensitivity to ${ }^{16} \mathrm{O}$ cross section for different stages of molten pool configurations from ERANOS calculations.
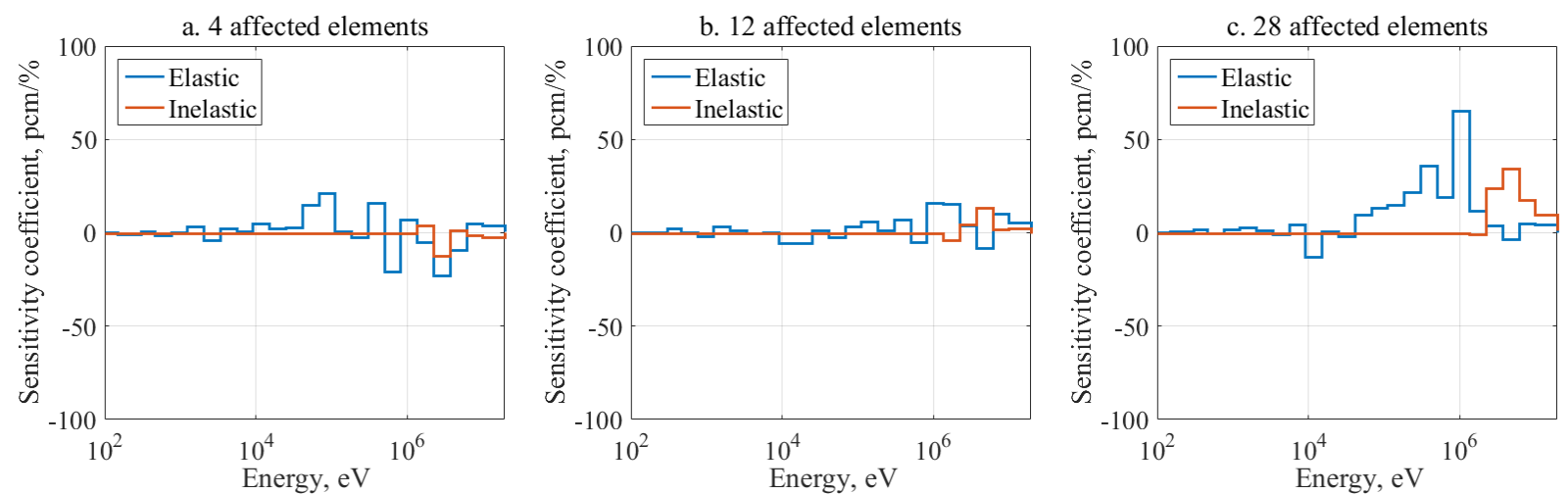

Figure 22: 33 group Na void sensitivity to ${ }^{56} \mathrm{Fe}$ cross section for different stages of molten pool configurations from ERANOS calculations. 

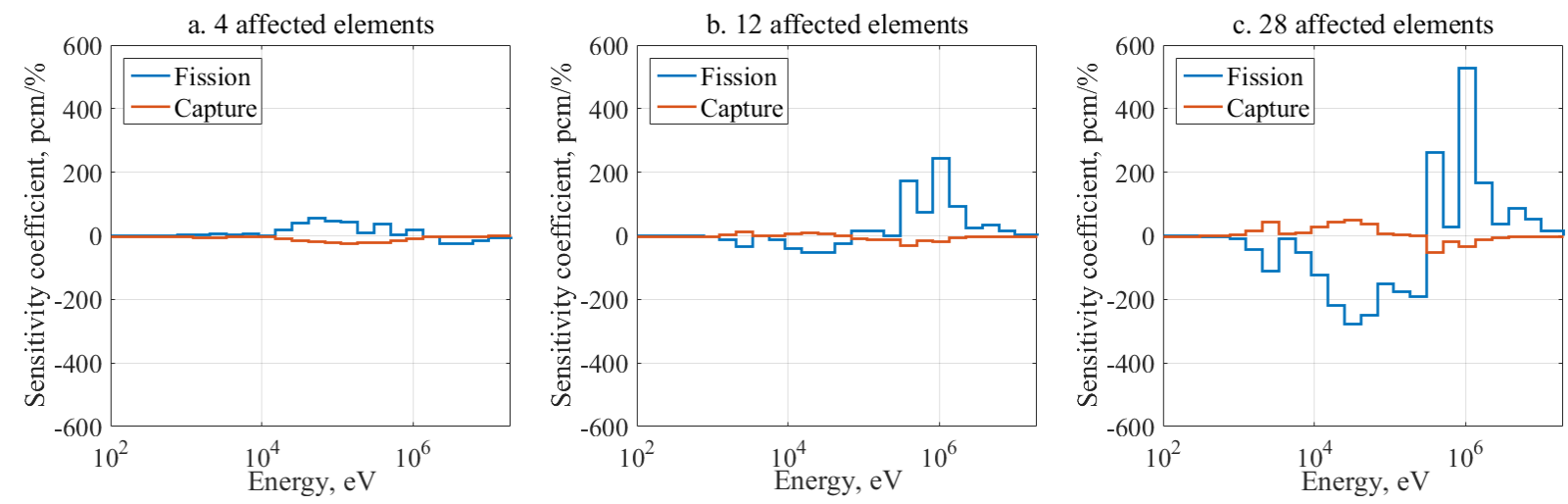

Figure 23: 33 group Na void sensitivity to ${ }^{235} \mathrm{U}$ cross section for different stages of molten pool configurations from ERANOS calculations.
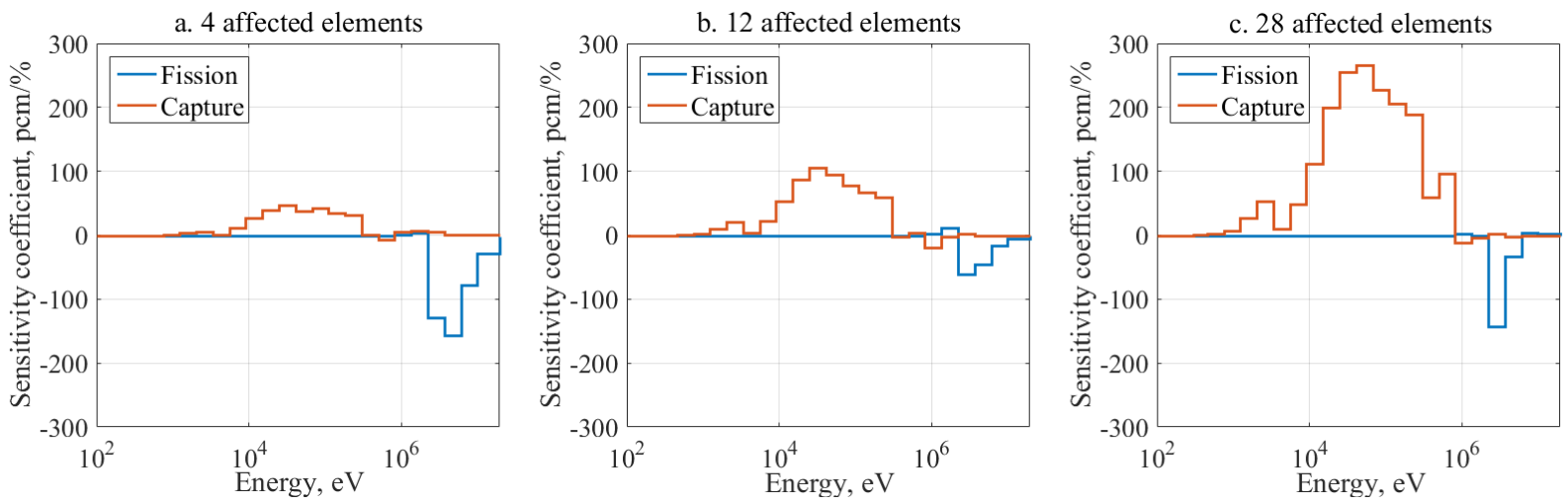

Figure 24: 33 group $\mathrm{Na}$ void sensitivity to ${ }^{238} \mathrm{U}$ cross section for different stages of molten pool configurations from ERANOS calculations. 


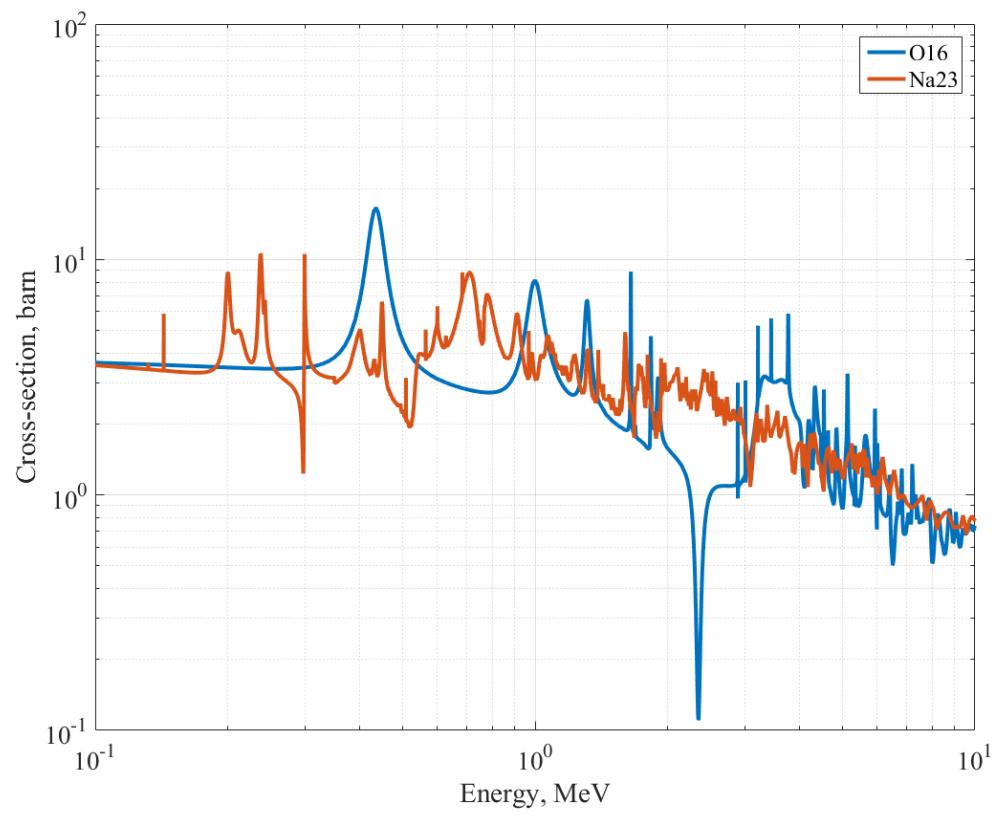

Figure 25: Comparison of elastic cross-section of ${ }^{16} \mathrm{O}$ and ${ }^{23} \mathrm{Na}$.

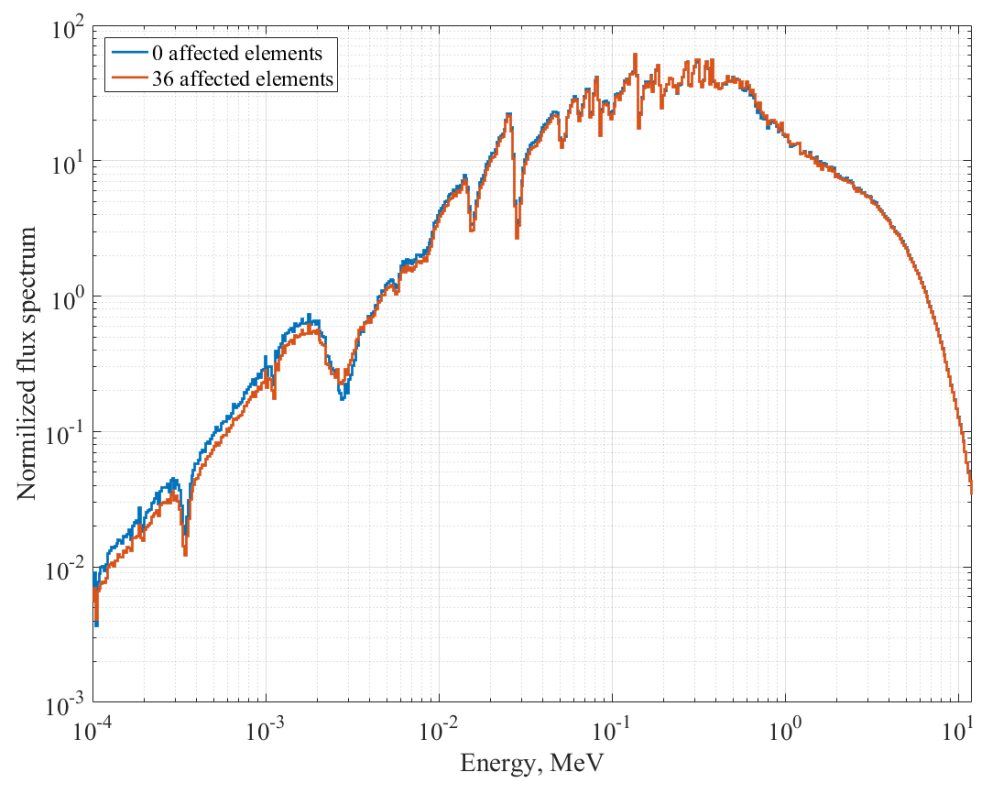

Figure 26: Comparison of elastic cross-section of ${ }^{16} \mathrm{O}$ and ${ }^{23} \mathrm{Na}$. 
Table 9: Summary of total uncertainty values for the SNEAK-12A reactivity changes due to sodium voiding and material relocation in pcm ( $\sigma$ )

\begin{tabular}{lccc}
\hline & Reaction included & Serpent-COMAC & ERANOS-COMAC \\
\hline \multirow{2}{*}{4 affected elements } & Correlated reactions only & 12.1 & 11.3 \\
& Cross-correlated reaction included & 14.7 & 10.4 \\
\hline \multirow{2}{*}{12 affected elements } & Correlated reactions only & 32.1 & 42.2 \\
& Cross-correlated reaction included & 33.0 & 41.8 \\
\hline \multirow{2}{*}{16 affected elements } & Correlated reactions only & 51.6 & - \\
& Cross-correlated reaction included & 55.4 & - \\
\hline \multirow{2}{*}{26 affected elements } & Correlated reactions only & 105 & - \\
& Cross-correlated reaction included & 108 & 97.9 \\
28 affected elements & Correlated reactions only & 111 & 93.9 \\
\cline { 2 - 4 } & Cross-correlated reaction included & 112 & - \\
\hline \multirow{2}{*}{36 affected elements } & Correlated reactions only & 139 & - \\
\hline
\end{tabular}

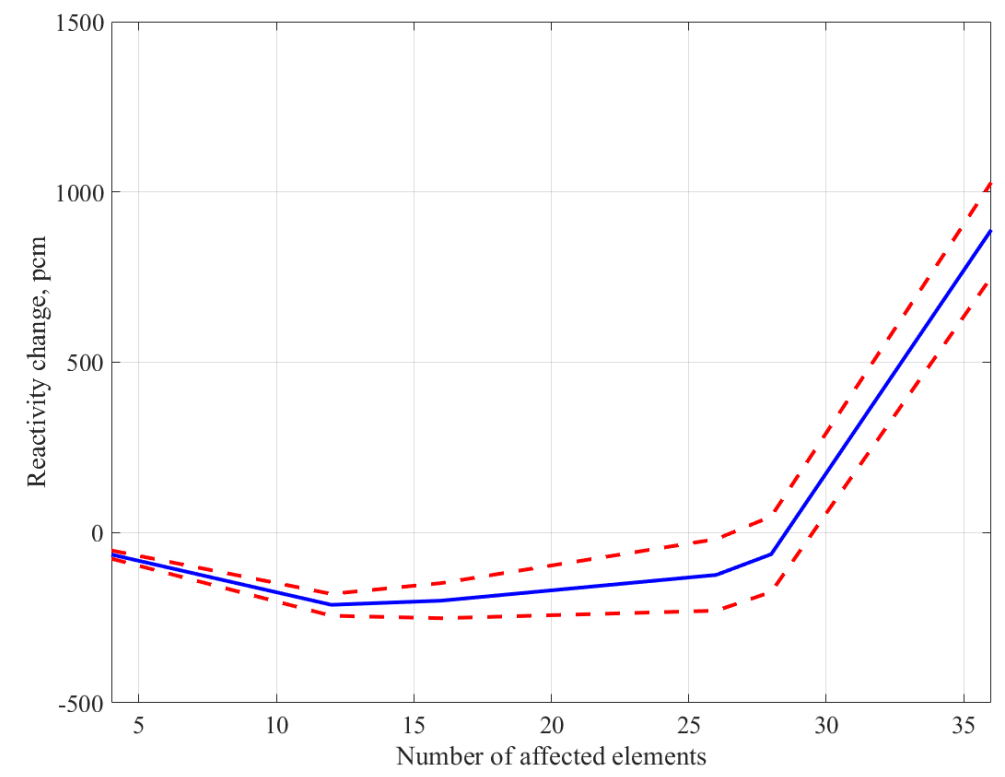

Figure 27: Molten pool reactivity changes with corresponding propagated uncertainties. 


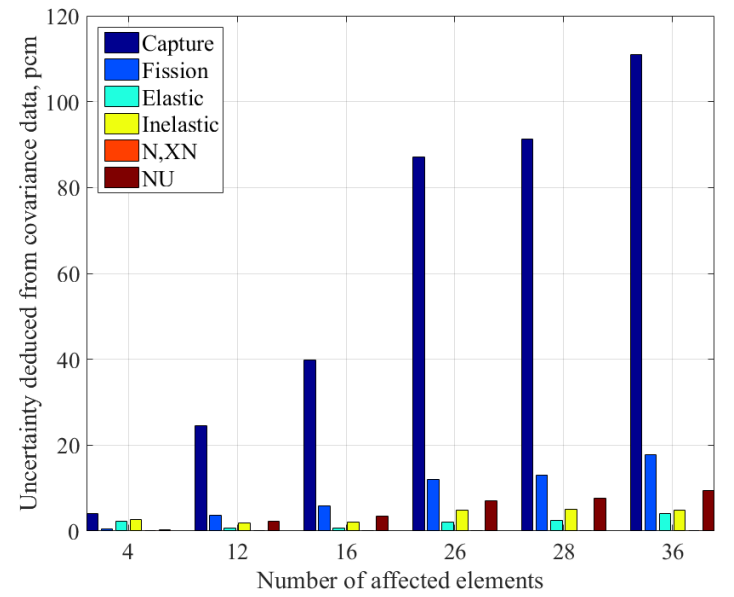

(a) ${ }^{235} \mathrm{U}$

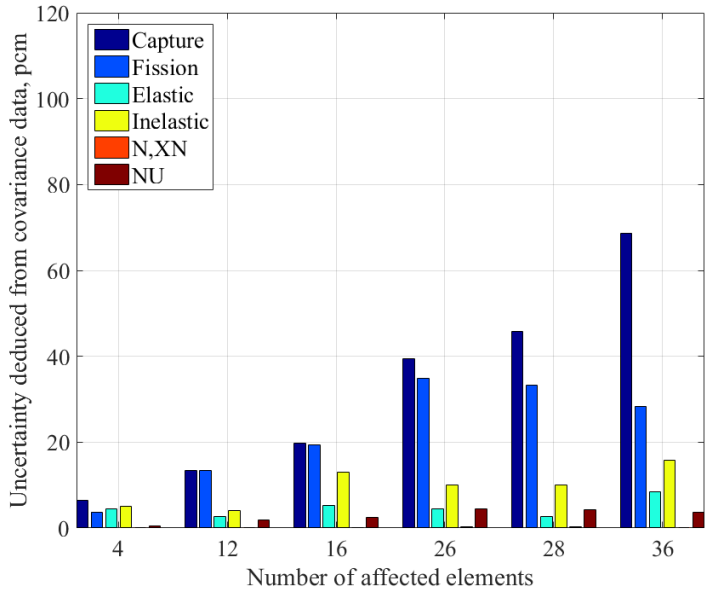

(b) ${ }^{238} \mathrm{U}$.

Figure 28: Uncertainties from different response contribution of the uranium isotopes calculated by Serpent.

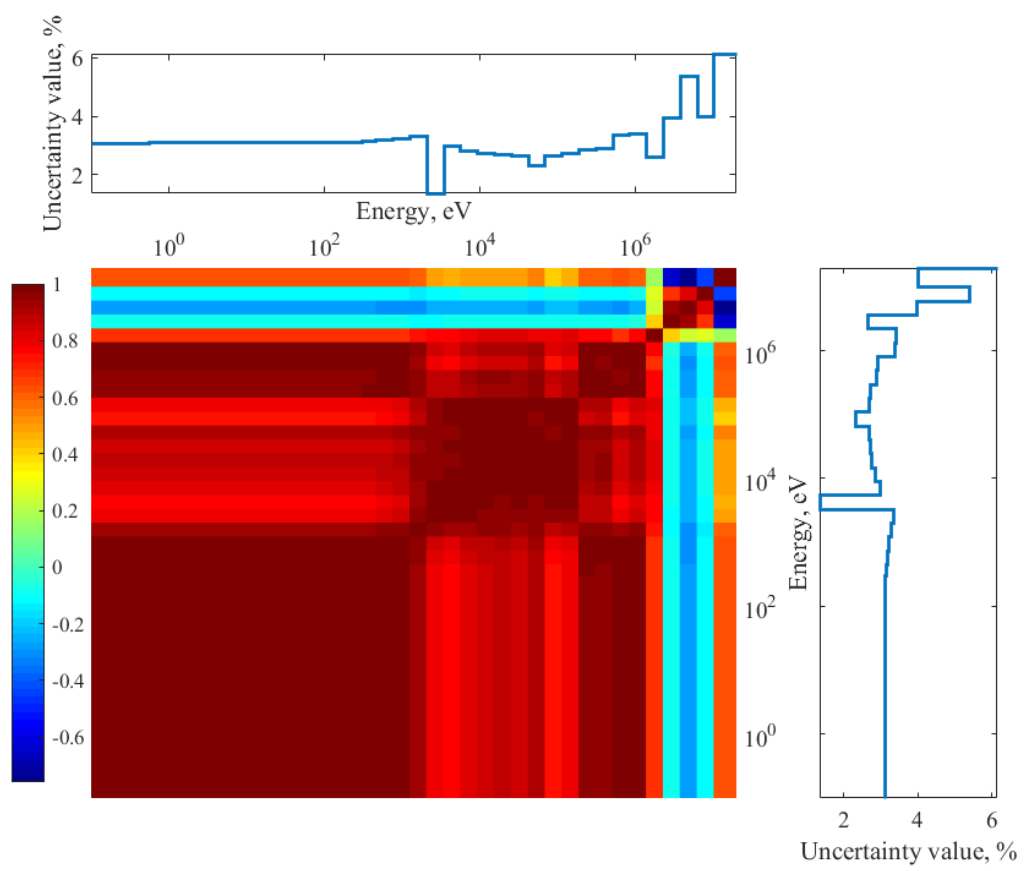

Figure 29: Covariance data for elastic scattering in ${ }^{23} \mathrm{Na}$ taken from the COMAC data. 


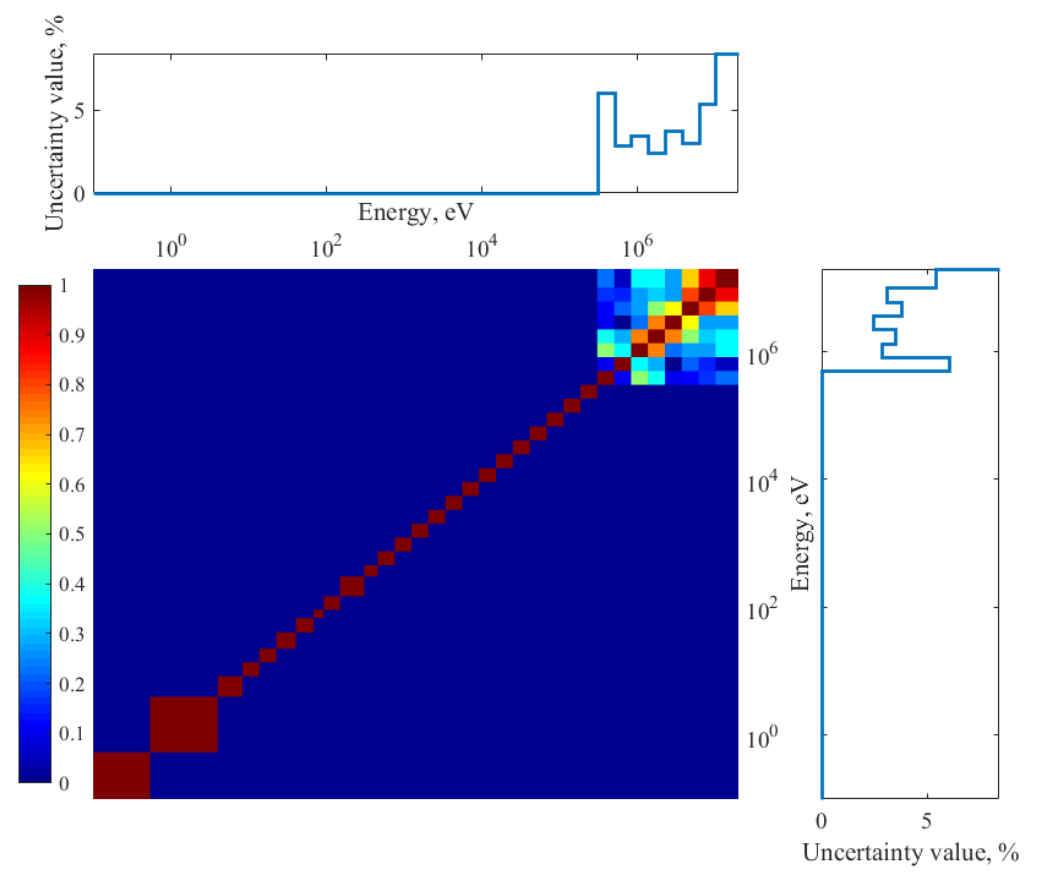

Figure 30: Covariance data for inelastic scattering in ${ }^{23} \mathrm{Na}$ taken from the COMAC data.

\subsection{Reactivity changes sensitivities in fuel slump-in configurations}

This subsection presents several additional experiments that were carried out during the SNEAK-12A program. The experimental configuration are presented in section 3 of this paper. The results for this part were performed solely by Serpent calculation, which showed to have excellent agreement with ERANOS calculations in the previous section. The first slump-in configuration corresponds to a complete channel sodium voiding with no modification to the core geometry (i.e the sodium plates in affected elements were replaced by empty steel cans). Therefore, it is possible to solely examine the sodium void effect and the associated nuclear data uncertainty propagation.

The total sensitivity coefficients of the small sodium void configuration (4 affected elements) are summarized in Table 10 for JEFF-3.1.1 and ENDF/B-VII nuclear data libraries. The results show that there is a very small sensitivity of the reactivity change (between voided and un-voided core) to the different isotopes cross-sections. If one neglects small numbers (below $1 \mathrm{pcm}$ ) for the small sodium void reactivity change (Table 10), there is almost no difference between JEFF-3.1.1 and ENDF/B-VII.1 nuclear data. On the other hand, the difference between the two nuclear data sets in the large configuration can reach a factor of two. This is a result of the impact of the $\Delta \rho$ in Eq. 4, the reactivity change obtained with the JEFF-3.1.1 library is two times larger with respect to the ENDF/B-VII value. As the reactivity change is given by an inverse value, this makes the total sensitivity values differ by a factor of 0.5 , which is the exact situation of Table 11.

The sensitivity profiles of different core configurations (void, small slump-in and large slump-in) are given in 
Table 10: Total sensitivity coefficient per nuclide calculated by Serpent for 3D model (small sodium void).

\begin{tabular}{lcc}
\hline Nuclide & Total - JEFF & Total - ENDF \\
\hline $\mathrm{C}-0$ & $<1.0 \mathrm{E}-06$ & $<1.0 \mathrm{E}-06$ \\
$\mathrm{O}-16$ & $i-1.0 \mathrm{E}-06$ & $7.213 \mathrm{E}-06$ \\
$\mathrm{Na}-23$ & $5.887 \mathrm{E}-06$ & $<1.0 \mathrm{E}-06$ \\
$\mathrm{Al}-27$ & $i-1.0 \mathrm{E}-06$ & $<1.0 \mathrm{E}-06$ \\
$\mathrm{Cr}-52$ & $1.359 \mathrm{E}-06$ & $<1.0 \mathrm{E}-06$ \\
$\mathrm{Fe}-56$ & $-3.030 \mathrm{E}-06$ & $<1.0 \mathrm{E}-06$ \\
$\mathrm{Ni}-58$ & $1.115 \mathrm{E}-06$ & $-1.926 \mathrm{E}-06$ \\
$\mathrm{U}-235$ & $-6.839 \mathrm{E}-06$ & $-1.097 \mathrm{E}-05$ \\
$\mathrm{U}-238$ & $4.070 \mathrm{E}-05$ & $4.454 \mathrm{E}-05$ \\
\hline Total & $3.466 \mathrm{E}-05$ & $3.985 \mathrm{E}-05$ \\
\hline
\end{tabular}

Table 11: Total sensitivity coefficient per nuclide calculated by Serpent for 3D model for large sodium void.

\begin{tabular}{lcc}
\hline Nuclide & Total - JEFF & Total - ENDF \\
\hline $\mathrm{C}-0$ & $<1.0 \mathrm{E}-06$ & $<1.0 \mathrm{E}-06$ \\
$\mathrm{O}-16$ & $<1.0 \mathrm{E}-06$ & $-1.786 \mathrm{E}-05$ \\
$\mathrm{Na}-23$ & $1.141 \mathrm{E}-06$ & $1.885 \mathrm{E}-05$ \\
$\mathrm{Al}-27$ & $1.414 \mathrm{E}-06$ & $2.605 \mathrm{E}-06$ \\
$\mathrm{Cr}-52$ & $-1.732 \mathrm{E}-06$ & $3.359 \mathrm{E}-06$ \\
Fe-56 & $<1.0 \mathrm{E}-06$ & $-5.213 \mathrm{E}-06$ \\
$\mathrm{Ni}-58$ & $1.222 \mathrm{E}-06$ & $<1.0 \mathrm{E}-06$ \\
$\mathrm{U}-235$ & $-1.422 \mathrm{E}-05$ & $-7.274 \mathrm{E}-06$ \\
$\mathrm{U}-238$ & $-5.766 \mathrm{E}-05$ & $-1.265 \mathrm{E}-04$ \\
\hline Total & $-6.282 \mathrm{E}-05$ & $-1.280 \mathrm{E}-04$ \\
\hline
\end{tabular}


Fig. 31 for the small affected region experiments, and in Fig. 32 for the large affected zone experiments. From the analysis of the small slump-in configuration analysis, the effect on the changes of the different configuration on the sensitivity profile of the sodium is almost none significant, probably due to the small affected region. This could not be said regarding the uranium isotopes, which have more profound behavior. The large configuration on the other hand are more profound and sharp due to the changes in the configurations.

The reactivity changes for the different experiments is summarized in Table 12 and the total propagated uncertainties are given in Table 13. The uncertainties for the experiments presented in this sub section continue to experience the same high values (relative ${ }^{\text {Patou: }}$ to the reactivity changes) as in the previous molten pool configurations. A single difference is the enhancement of the uncertainties when modeling larger fuel slumping, the ratio between the different uncertainties remains approximately constant (1:4). The uncertainty values in these experiments remains quite low in comparison to the molten pool experiments, this might be because of a smaller experimental configuration in respect to the molten pool configuration, despite the large changes in the reactivity.

Table 12: Reactivity changes between different slump-in configurations obtained from Serpent calculations, in pcm.

\begin{tabular}{lcc}
\hline Experiment type & Small & Large \\
\hline Sodium void & -60.95 & -168.50 \\
Small slump-in & -41.59 & -94.64 \\
Large slump-in & 552.81 & 2503.05 \\
\hline
\end{tabular}

Table 13: Summary of total uncertainty values for the SNEAK-12A reactivity changes due to fuel slump in in pcm

\begin{tabular}{cccc}
\hline & Reaction included & Small & Large \\
\hline \multirow{3}{*}{ Sodium void } & Correlated reactions only & 6.9 & 27.7 \\
& Cross-correlate reaction included & 6.1 & 24.4 \\
\hline \multirow{2}{*}{ Small slump-in } & Correlated reactions only & 9.0 & 28.7 \\
& Cross-correlate reaction included & 7.6 & 26.6 \\
\hline \multirow{3}{*}{ Large slump-in } & Correlated reactions only & 20.6 & 85.1 \\
& Cross-correlate reaction included & 18.2 & 73.9 \\
\hline
\end{tabular}

\section{Conclusions}

A complete sensitivity and uncertainty analysis has been performed for Na void and material slump-in experiments carried out in the SNEAK-12A experimental phase. The exercise was done as an attempt to identify important cross 

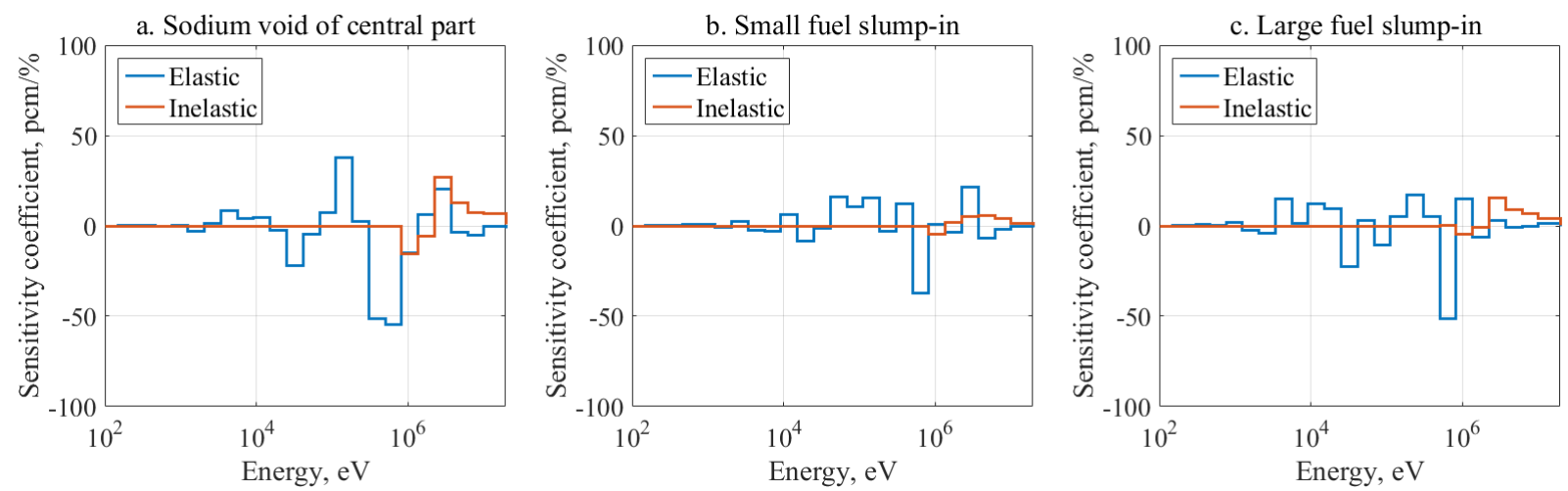

(a) ${ }^{23} \mathrm{Na}$ cross-sections.
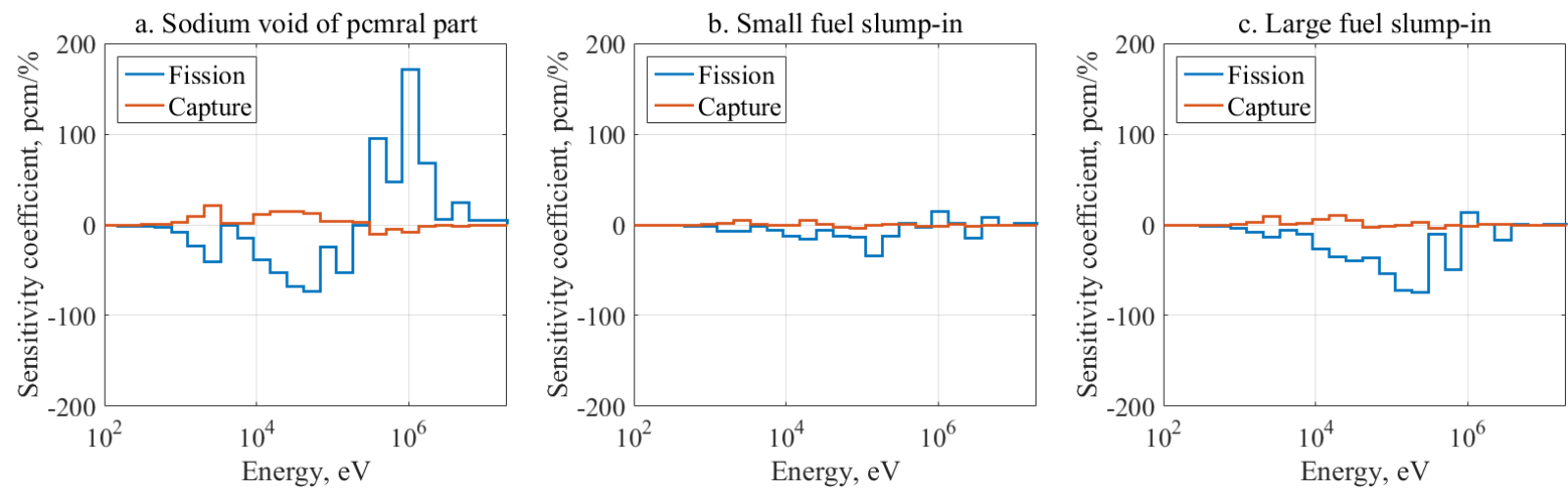

(b) ${ }^{235} \mathrm{U}$ cross-sections.
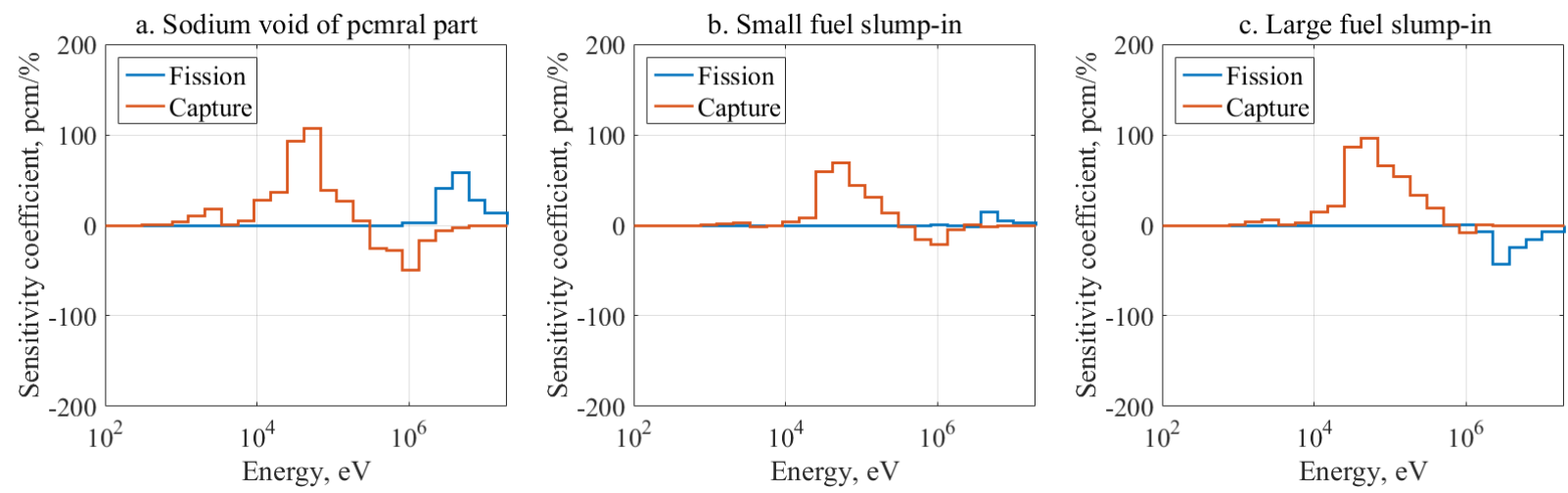

(c) ${ }^{238} U$ cross-sections.

Figure 31: Small slump in configurations sensitivity to different isotope cross-sections. 

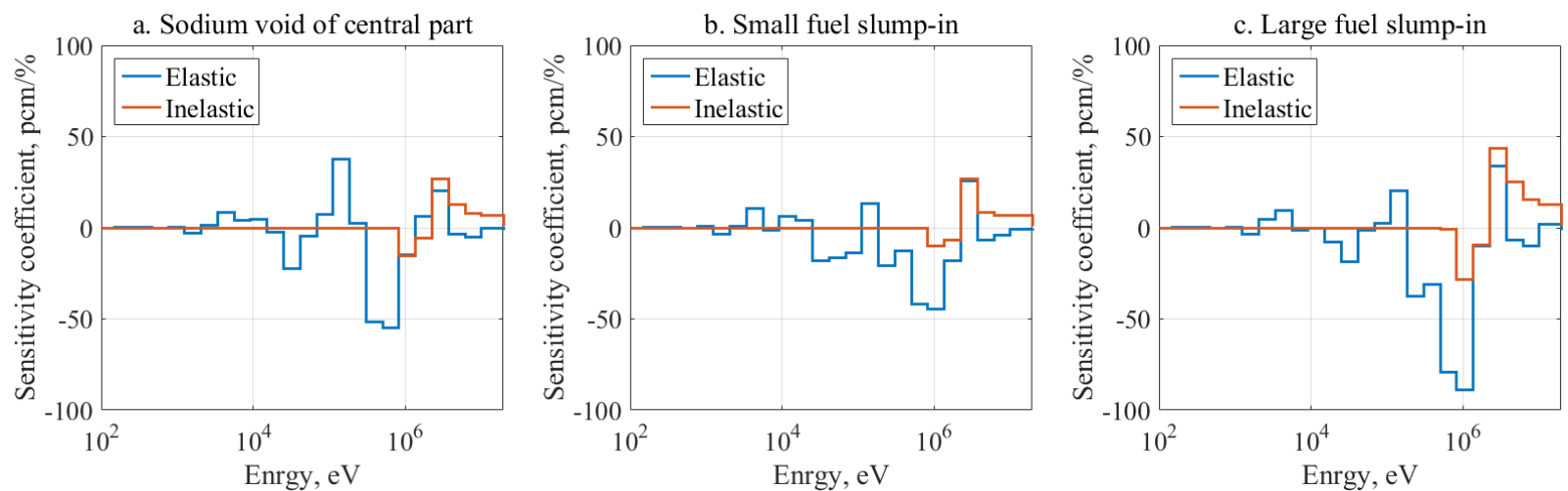

(a) ${ }^{23} \mathrm{Na}$ cross-sections.
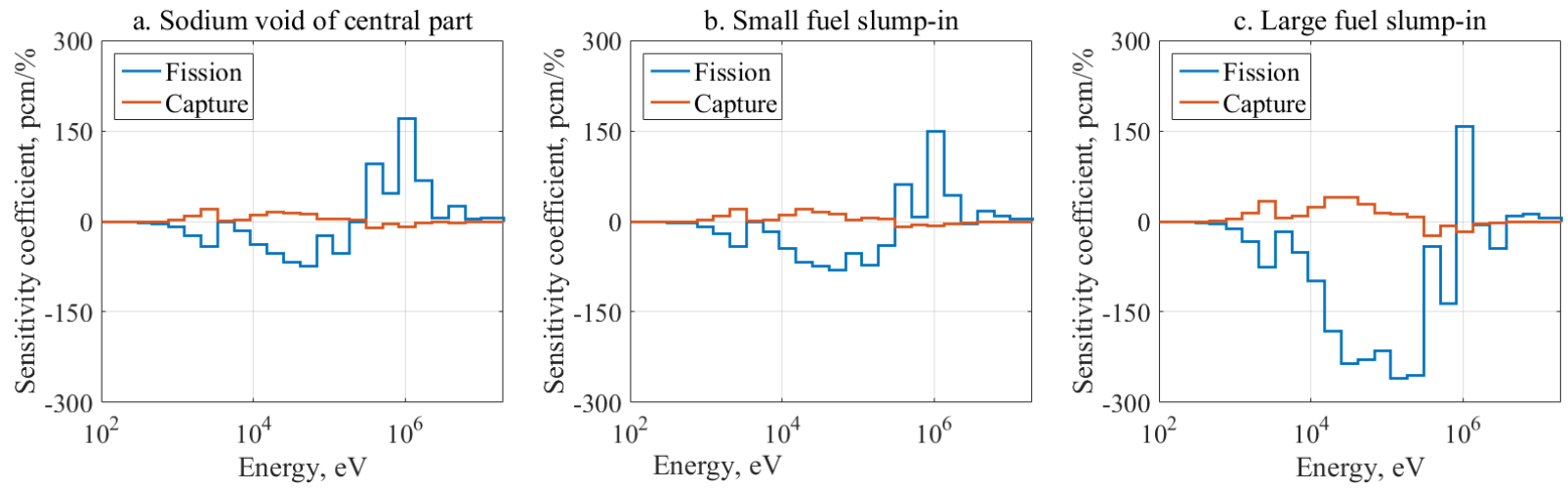

(b) ${ }^{235} \mathrm{U}$ cross-sections.
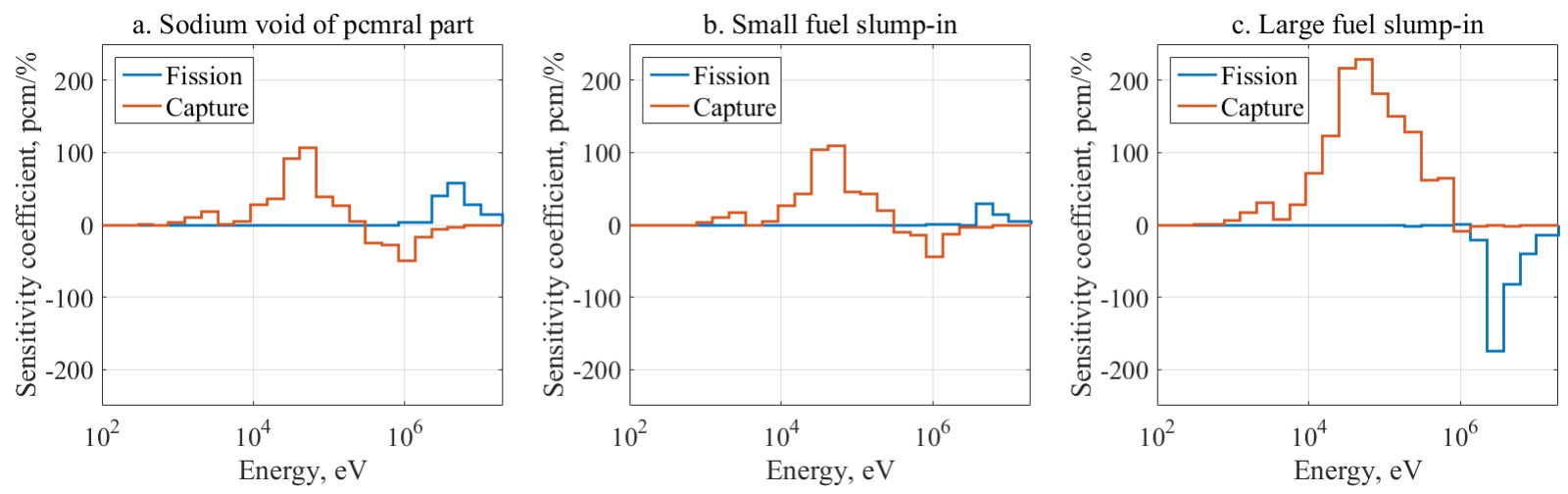

(c) ${ }^{238} U$ cross-sections.

Figure 32: Large slump in configurations sensitivity to different isotope cross-sections. 
sections in terms of propagated uncertainties reduction on reactivity effects during core degradation sequences in SFRs. The assessment of those ND uncertainties is essential for designing future experiments, whose aim is to improve our current knowledge of SA situations and to infer best estimate ND covariances, as a way to properly anticipate risk of prompt criticality with high accuracy. The calculation of sensitivity coefficients was carried our utilizing ERANOS, a well established code for fast reactor application, and the newly implemented capabilities for those calculations in the Serpent 2 continuous energy Monte Carlo code. Both calculations are base on the JEFF-3.1.1 evaluation. Additional comparison to ENDF/B-VII nuclear data calculation were also carried out in Serpent 2.

The sensitivity analysis on the clean core configuration showed an excellent agreement between ERANOS and Serpent, with no significant deviations that could not be attributed to the slight difference in material balance and geometry changes due to the utilization of R-Z model in ERANOS. In addition to code-to-code comparison, an impact of the different libraries on the sensitivity coefficients was performed. The results, excluding some low abundance materials in the core and some reactions with very low impacts (high statistical error, e.g N,xN in non-fissile materials), the major discrepancies were found in the sodium inelastic-scattering cross section, and in the inelastic scattering of the uranium isotopes. The main difference in the sodium sensitivity coefficients is embedded in the cross-section data, which was discussed in section 2.2.

The uncertainty analysis of the clean core experiment, based on the COMAC covariance data, showed a large uncertainty propagated from the nuclear data, a total of $2500 \mathrm{pcm}$, where the main contributors to the uncertainties were the capture in the uranium isotopes. Comparing the total uncertainty value to a typical fast lattice (e.g. SFR, LMFBR) reveals that in the SNEAK-12A core case the value is about two times higher. However, this comparison is not a fare one due to the different fuels that are loaded in each system (metallic uranium in the SNEAK-12A vs. MOX in typical fast system). This however, is a pure impact of the very high core materials density.

The final stage included examination of the uncertainty propagation on different reactivity changes caused by core distortions. The first configuration to be considered were the molten pool configuration. For those configurations, a comparison between Serpent and ERANOS was made, including the same covariance data (COMAC). The results were presented in Table 8 for the reactivity changes and Table 9 of the molten pool configurations. The results showed that the uncertainty magnitude is growing as the molten pool configuration is getting larger. The uncertainty values are varying from about $20 \%$ of $\Delta \rho$ when the values of the $\Delta \rho$ are the lowest and the highest, to about $170 \%$ at the point when the $\Delta \rho$ changes signs. In the case of the small and large slump-in configuration, the reactivity changes are less pronounced than in the molten pool cases, as summarized in Table 12 and 13. However, they are also non negligible for the sodium voiding and the fuel slump in, where the uncertainties are varying between 10-20\% of $\Delta \rho$ for the small configurations and $15-30 \%$ of $\Delta \rho$ for the larger configurations. On the other hand, when large slump-in configuration were considered, the reactivity uncertainty remains small (3.5\% of $\Delta \rho$ for small and large configuration). This is mainly due to the sharp reactivity increase in those experiments.

The results of this work indicate still high uncertain values in several of the investigated isotopes cross-sections, mainly of ${ }^{235} \mathrm{U}$ fission and ${ }^{238} \mathrm{U}$ capture. The SNEAK-12A series of experiment is an excellent benchmark database 
for improving ND knowledge in case of SA situation, and can be used for enabling a better prediction of reactivity effeects, and prepare the future experimental design of such additional program in the ZEPHYR facility. 


\section{References}

Gandini, A., Palmiotti, G., \& Salvatores, M. (1986). Equivalent generalized perturbation theory (EGPT). Annals of Nuclear Energy, $13,109-114$.

Helm, F., \& Henneges, G. (1985). Measurments and Calcualtion of Reactivity Effects of Material Rearrangments in a Plutonium-Fueled Fast Reactor Rod Lattice. Nuclear Technology, 71, 68-81.

Helm, F., Henneges, G., \& Maschek, W. (1984). Measurements and Computation of the Reactivity Effects of Accident-Caused Core Distortions in Liquid-Metal Fast Breeder Reactors. Nuclear Science and Engineering, 87, 295-313.

Kaiser, R. E., Beck, C. L., \& Lineberry, M. J. (1976). Simulation of an HCDA sequence on the ZPPR critical facility. In Proc. ANS/ENG Mtg. Fast Reactors Safety and Related Physics. Chicago, IL, USA: American Nuclear Society.

Leppanen, J., Pusa, M., Viitanen, T., Valtavirta, V., \& Kaltiaisenaho, T. (2015). The Serpent Monte Carlo code: Status, development and applications in 2013. Annals of Nuclear Energy, 82, 142-150.

Margulis, M., Blaise, P., \& Gilad, E. (2016a). Advanced Small and Large Core Distortions Modeling in ZPR to Assess Core Recriticality Scenarios of SFR Core Degradation Sequences. In Proc. Int. Conf. IGORR-2016. Berlin, Germany: European Nuclear Society.

Margulis, M., Blaise, P., \& Gilad, E. (2016b). Monte Carlo Analysis of SNEAK-12A Core Disruption in Liquid-Metal Fast Breeder Reactors - The Path for Innovative Severe Accidents Studies in ZPR. In Proc. Int. Conf. PHYSOR-2016. Sun Valley, ID, USA: American Nuclear Society.

Nakano, M., Tsunoda, H., \& Hirota, J. (1984). An Experimental Study of Reactivity Changes and Flux Distortion in Simulated LMFBR Meltdown Cores. Nuclear Science and Engineering, 294, 283-294.

Palmiotti, G., Salavatores, M., \& Aliberti, G. (2015). A-priori and A-posteriori covariance data in nuclear cross section adjusment: Issuses and challanges. Nuclear Data Sheets, 123, 41-50.

Rimpault, G., Khamakhem, W., Jacqmin, R., Sublet, J. C., \& Tommasi, J. (2007). Sodium cross sections and covariance data for the assessment of SFR neutronic characteristics . In Proc. Int. Workshop NEMEA-4. Prague, Czech Republic: IAEA.

Rimpault, G., Plisson, D., Tommasi, J., Jacqmin, R., Rieunier, J.-M., Verrier, D., \& Biron, D. (2002). The ERANOS Code and Data System for Fast Reactor Neutronic Analysis. In Proc. Int. Conf. PHYSOR-2002. Seoul, South Korea: American Nuclear Society.

Salvatores, M., Jacqmin, R., Ailberti, G., Dunn, M., Hogenbirk, A., Ignatyuk, A., Ishikawa, M., Kodeli, I., J, K. A., McKnight, R., Mills, R. W., Oblozinsky, P., Palmiotti, G., Plompen, A., Rimpault, G., Rugama, Y., Talou, P., \& Yang, W. S. (2008). Uncertainty and Target Accuracy Assessment for Innovative Systems Using Recent Covariance Data Evaluation. Technical Report January.

Salvatores, M., Palmiotti, G., Alberti, G., Archier, P., De Saint Jean, C., Dupont, E., Herman, M., Ishikawa, M., Ivanova, T., Ivanov, E., Kim, S. J., Manturov, G., McKnight, R., Pelloni, S., Plompen, A. J. M., Rearden, B. T., Rochman, D., Sugino, K., Trkov, A., Wang, W., Wu, H., \& Yang, W. S. (2014). Methods and issues for the combined use of integral experiments and covariance data: Results of a NEA international collaborative study. Nuclear Data Sheets, 118, 38-71. 
Santamarina, A., Bernard, D., Blaise, P., Coste, M., Courcelle, A., Huynh, T. D., Jouanne, C., Leconte, P., Litaize, O., Mengelle, S., Nouere, G., Ruggieri, J.-M., Serot, O., Tommasi, J., Vaglio, C., \& Vidal, J.-F. (2009). The JEFF-3.1.1 Nuclear Data Library, JEFF Report 22, Validation Results from JEF-2.2 to JEFF-3.1.1. Technical Report.

Santamarina, A., Bernard, D., Dos Santos, N., Vaglo, C., \& Leal, L. (2012). Re-estimation of Nuclear Data and JEFF-3.1.1 Uncertainty Calcualtions. In Proc. Int. Conf. PHYSOR-2012. Knoxville,TEN,USA: American Nuclear Society.

Tommasi, J., Archier, P., \& Ruggieri, J. M. (2010). Validation of the sodium void reactivity effect prediction using JEFF-3.1 nuclear data. Annals of Nuclear Energy, 37, 1534-1553. 